\title{
HACIA LA ECONOMÍA DEL CONOCIMIENTO: EL CAMINO PARA CRECER CON EQUIDAD EN EL LARGO PLAZO*
}

\author{
Nicolás Eyzaguirre, Mario Marcel, \\ Jorge Rodríguez y Marcelo Tokman
}

Chile comenzó a experimentar un crecimiento alto y sostenido desde que, abandonando la estrategia de desarrollo hacia adentro, sentó las bases de una estrategia de desarrollo compatible con sus ventajas comparativas y ordenó sus políticas macroeconómicas — lo que ocurrió alrededor de 1985. Cuando lo anterior se reforzó y complementó - a partir de 1990 - con un Estado no ingenuo ni prescindente, corrector de fallas de mercado, proveedor de bienes e infraestructura pública y protección social, también se comenzaron a evidenciar avances en términos de equidad, principalmente en lo referido a reducción de la pobreza. Sin embargo, de la observación de la evidencia internacional se desprende que, a pesar de los éxitos de los últimos veinte años, existen limitantes en el modelo de desarrollo vigente en Chile que deben ser enfrentadas de manera proactiva. En

Nicolás EyZAGuIRRe. Ministro de Hacienda.

Mario Marcel. Director de Presupuesto, Ministerio de Hacienda.

Jorge Rodríguez C. Asesor del Ministerio de Hacienda.

Marcelo Tokman. Coordinador de Política Económica, Ministerio de Hacienda.

* Este documento está basado en el Capítulo IV de la Exposición Sobre el Estado de la Hacienda Pública, presentada ante el Congreso Nacional en octubre de 2004.

Los autores agradecen la colaboración de José Miguel Benavente, Stephen Blackburn, Rodrigo Morales y Carla Tokman. 
efecto, la señal de alerta aparece al verificar que nuestro país es claramente más dependiente de sus recursos naturales y presenta una distribución del ingreso mucho menos equitativa que los países en el próximo nivel de desarrollo.

En este contexto, el presente estudio postula el imperativo de transitar gradualmente desde el modelo primario exportador hacia la economía del conocimiento como requisito indispensable para continuar creciendo y lograr la equidad en el largo plazo. En contraste con la concepción tradicional de agregar valor a las exportaciones en un proceso de encadenamiento hacia adelante, la estrategia aquí delineada acepta la centralidad de los "commodities" donde el país tiene ventajas comparativas en el menú exportador, pero postula su mayor articulación con el resto de la economía en encadenamientos laterales y hacia atrás donde el capital humano y el avance tecnológico jueguen un rol cada vez más preponderante. En particular, plantea que esta estrategia se construye sobre tres pilares: (i) un régimen institucional y de incentivos económicos claro, coherente y estable; (ii) una fuerte capacidad de innovación, orientada a desarrollar encadenamientos productivos en torno a ventajas comparativas; y (iii) un capital humano de calidad. Se diagnostica que Chile está en buen pie en el primero de estos pilares, pero presenta importantes rezagos en los dos últimos, no obstante los importantes avances logrados en materia educacional desde 1990. Se argumenta que en ambos pilares — capacidad de innovación y capital humano- existen espacios para un mayor y mejor rol del Estado, y se plantean lineamientos de políticas públicas para cerrar las brechas que nos separan de aquellos países que han logrado desarrollarse en base a la economía del conocimiento en torno a los recursos naturales.

\section{La estrategia de crecimiento chilena y su sustentabilidad}

\subsection{Reseña histórica ${ }^{1}$}

\section{L}

uego de la Gran Depresión de los años 30, y hasta estos días, Chile ha ensayado dos grandes modelos de desarrollo, opuestos entre sí. El primer modelo, la "estrategia de desarrollo hacia adentro" (1934-1973, aproximadamente), se frustró al no lograr consolidar una industrialización basada en la sustitución de importaciones para abastecer el mercado inter-

${ }^{1}$ Para mayores antecedentes históricos, véase Ffrench-Davis (2003), Meller (1998) y Sunkel (1991). 
no y, eventualmente, el latinoamericano. Si bien en una primera etapa este proceso fue motivado por señales de mercado - la Gran Depresión implicó una escasez de productos importados que incentivó su producción interna-, en una segunda y prolongada etapa fue el Estado el que jugó un papel activo y deliberado en el intento de alcanzar una mayor independencia económica del resto del mundo extra-regional. Esta estrategia, por ser inconsistente con las ventajas comparativas naturales del país, resultó en cuantiosas ineficiencias. Dichas ineficiencias se hicieron evidentes en la protección de "industrias nacientes" — principalmente mediante trabas arancelarias y créditos subsidiados - que raramente llegaron a la madurez $^{2}$. Adicionalmente, el énfasis en la sustitución de importaciones generó el estancamiento de la agricultura y desincentivó el desarrollo de las exportaciones. Estos problemas se vieron acentuados por la estrechez del mercado interno, la integración de los mercados latinoamericanos que no se materializó ni en la profundidad ni a la velocidad esperada, y la persistente dependencia de los bienes de capital importados necesarios para sustentar la industrialización. Todo esto a la larga generó recurrentes crisis de balanza de pagos $^{3}$.

Si bien esta estrategia generó un cierto crecimiento, lo hizo a tasas insuficientes (véase Gráfico $\mathrm{N}^{\circ} 1$ ) que no permitieron cerrar las brechas con los países más desarrollados. Así, en el período 1934-1973 el PIB por habitante creció a un promedio anual de sólo $2,1 \%{ }^{4}$.

El segundo modelo, la "estrategia de crecimiento hacia afuera" (1974-), puede separarse en tres etapas. Durante la primera (hasta 1985, aproximadamente) se establecieron las bases para explotar las ventajas comparativas del país, con una activa y casi exclusiva participación del sector privado en la producción de bienes y servicios y, en particular, en la exportación de recursos naturales. Ello se logró a través de la eliminación de los controles de precios y subsidios, la liberalización unilateral del sector externo y la liberalización del mercado financiero. En todos estos ámbi-

${ }^{2}$ El concepto de "industria naciente" asumía que las empresas por el solo hecho de envejecer y aumentar de tamaño se harían más productivas, lo que no tiene fundamento empírico (Bruton, 1998).

${ }^{3}$ Aun si la integración regional hubiere procedido con mayor celeridad, esta estrategia tenía escasa probabilidad de éxito, debido a que el país no tenía, ni tiene, ventajas comparativas en la elaboración de manufacturas. Por una parte, estamos alejados de los centros más dinámicos de consumo de bienes manufacturados y, por otra, no tenemos la abundancia de mano de obra semi-calificada requerida para aprovechar economías de escala en su producción.

${ }^{4}$ En igual período, el PIB por habitante de Japón creció a un promedio anual de 4,3\%, el de EE.UU. a 3,2\%, y el de Francia a 2,9\%. Para mayores detalles, véase Braun et al. (2000). 
GRÁFICO N ${ }^{\circ}$ 1: $\quad$ EVOLUCIÓN DEL PIB POR HABITANTE, CHILE 1934-2003

(Pesos de 1995)

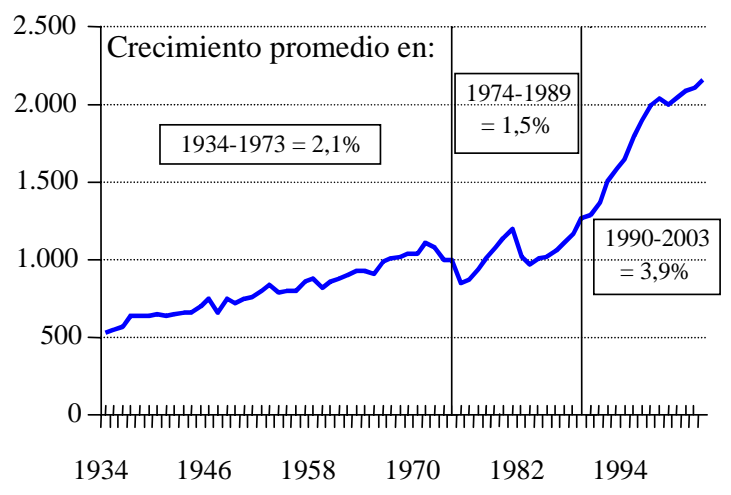

Fuente: Elaborado por los autores sobre la base de Braun et al. (2000), Banco Central y Boletín Demográfico INE-Celade.

tos, así como en el impulso privatizador de la producción, Chile fue un reformador pionero.

Sin embargo, esta etapa no generó un crecimiento alto y sostenido debido, fundamentalmente, a un muy inadecuado manejo macroeconómico y a una regulación insuficiente del mercado financiero. Estas deficiencias produjeron la exacerbación de las crisis internacionales de 1975 y 1982, con caídas en el producto doméstico de más de $13 \%$ y $15 \%$, respectivamente. Asimismo, durante esta etapa se verificó un marcado deterioro de las condiciones sociales y de la infraestructura física y social, debido a que el Estado fue minimizado a tal nivel que simplemente se ignoraron las fallas de mercado, deficiencias que son particularmente críticas en las economías en desarrollo. Así, los monopolios de servicios públicos privatizados no fueron debidamente regulados y los bienes de infraestructura pública y social no fueron adecuadamente provistos. Además, la población más carente no contó con una red de protección social suficiente, puesto que se esperaba que ésta se beneficiase automáticamente del crecimiento económico, lo que ciertamente no ocurrió.

Una vez superada la crisis de 1982 se vivió una segunda etapa del modelo aperturista (1985-1989) en la que se corrigieron las deficiencias más evidentes del manejo macroeconómico y de regulación del sistema financiero. Ello permitió reducir la volatilidad macroeconómica y sentar las bases para volver a crecer. En efecto, en el período 1985-1990 el PIB por 
habitante creció a una tasa promedio anual de 4,6\% - mientras que entre 1974 y 1984 el crecimiento anual fue de sólo 0,1\% - expansión que se vio favorecida por el mejor ambiente externo y la capacidad ociosa heredada de la crisis. No obstante este resultado, hasta 1990 persistió un Estado ingenuo —o más bien prescindente- en términos de regulación de monopolios y pasivo en la provisión de infraestructura y protección e inversión social. De hecho se siguió minimizando el tamaño del Estado, lo que se manifiesta en la caída de 6,6 puntos porcentuales de la carga tributaria como porcentaje del PIB entre 1984 y 1989.

Considerando las dos primeras etapas como un todo (1974-1989), los resultados de la aplicación del "modelo de crecimiento hacia fuera" con un Estado "ingenuo-prescindente" $\mathrm{y}$, en la mayor parte, con un marco macroeconómico inadecuado, fueron mediocres: un bajo y volátil crecimiento del PIB por habitante, que en promedio alcanzó a un magro 1,5\% anual (véase Gráfico $\mathrm{N}^{\circ} 1$ ). Las consecuencias del período en materia de equidad fueron incluso peores: las asignaciones familiares, las remuneraciones y el gasto social en educación y salud se redujeron fuertemente ${ }^{5}$; el desempleo y la pobreza aumentaron significativamente ${ }^{6}$; y la distribución del ingreso se hizo mucho más desigual ${ }^{7}$.

\subsection{Estrategia vigente desde 1990}

A partir de 1990 los gobiernos democráticos se plantearon el desafío de lograr un crecimiento económico dinámico y sostenido que beneficiase de manera más equitativa a los distintos estratos de la sociedad. Ciertamente este era un desafío mayor, considerando las enormes frustraciones acumuladas tanto por el modelo de economía cerrada, como por una década y media de apertura económica con magros resultados. Esta frustración, aunque con estrategias económicas diferentes, recorría también al resto de Latinoamérica ${ }^{8}$.

${ }^{5}$ En términos reales, la asignación familiar alcanzó en 1989 un valor equivalente a sólo el 28,4\% del valor de 1970 . Por su parte, las remuneraciones reales cayeron en promedio cerca de un $9 \%$ en igual período; mientras que el gasto social lo hizo en más de un $16 \%$, con una caída cercana al 38\% en educación (Ffrench-Davis, 2003).

${ }^{6}$ La primera medición de la pobreza, efectuada en 1987 a través de la encuesta CASEN, muestra que la población en dicha condición era al menos un $45,1 \%$. En cuanto a la tasa de desocupación, ésta se elevó a 17,6\% en 1975 y a 31,3\% en 1983 (considerando a las personas en programas de emergencia como desempleados). Sólo a partir de 1989 se retornó a una tasa de un dígito (Ffrench-Davis, 2003).

${ }^{7}$ Las Encuestas de Presupuestos Familiares efectuadas por el INE en el Gran Santiago muestran que la razón entre el gasto del quintil más rico y el del quintil más pobre aumentó de 5,86 en 1969, a 12,48 en 1988 (Ffrench-Davis, 2003).

${ }^{8}$ Fajnzylber (1990). 
La estrategia base de esta tercera etapa del "modelo de crecimiento hacia fuera" ha consistido en combinar las ganancias de eficiencia de una economía abierta y orientada al mercado, con un Estado no ingenuo ni prescindente, capaz de corregir las fallas de mercado, proveer infraestructura y bienes públicos, materializar inversión social y brindar una red de protección social focalizada en la población más carente. Asimismo, se ha profundizado el ordenamiento del marco macroeconómico, la regulación de los monopolios naturales, la preservación de la fe pública y la supervisión y desarrollo del mercado de capitales, lo que ha permitido disminuir aún más la volatilidad y potenciar la eficiencia de la economía.

En particular, la estrategia de crecimiento ha profundizado la orientación de la capacidad productiva hacia las exportaciones, expandiendo la apertura de las fronteras económicas, fomentando la competencia y una asignación eficiente de los recursos a través de mecanismos de mercado y estableciendo reglas económicas claras y parejas. Ello ha posibilitado que el sector exportador se haya consolidado como el principal motor de crecimiento y aumento de productividad, con un énfasis en el desarrollo y aprovechamiento de nuestras ventajas comparativas en recursos naturales (véase Gráfico $\mathrm{N}^{\circ}$ 2). En años recientes este enfoque de apertura se ha seguido fortaleciendo a través de la suscripción de tratados de libre comercio con los principales socios comerciales de Chile y la negociación de diversos acuerdos de doble tributación, entre otras iniciativas.

GRÁFICO N ${ }^{\circ}$ 2: $\quad$ COMPOSICIÓN DE LAS EXPORTACIONES DE CHILE, 2002

(\% del total de exportaciones)

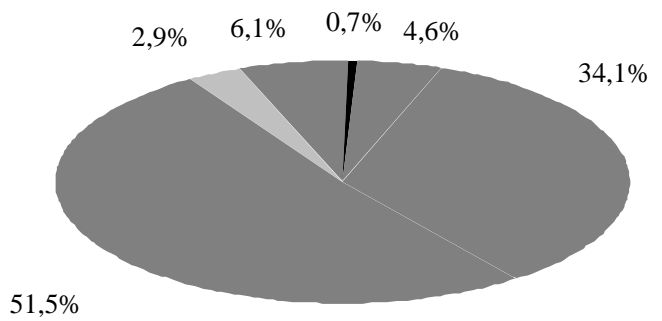

Productos primarios

Manufacturas basadas en RRNN

Manufacturas de baja tecnología

Manufacturas de media tecnología

Manufacturas de alta tecnología

Otras transacciones

Fuente: Elaborado por los autores sobre la base de estadísticas CEPAL. 
Para reforzar el compromiso con la equidad ha sido clave complementar los beneficios del crecimiento económico general con la construcción de una sólida red de protección social. En este ámbito destacan el aumento de los subsidios monetarios y las pensiones, la creación del seguro de cesantía, el programa Chile Solidario y la reforma a la salud. Para financiar esta red se debió detener la tendencia decreciente de la carga tributaria promovida por la estrategia del período 1974-1989 —en especial a partir de 1984-, cuyo compromiso con la equidad se reducía casi exclusivamente a su fe en la "teoría del chorreo". En cuanto a los logros de la estrategia vigente, el tiempo transcurrido evidencia avances importantes, tanto en términos de crecimiento económico como en términos de equidad. No obstante, persiste el desafío de mejorar la distribución del ingreso autónomo y continuar con la reducción de la pobreza.

\subsection{Sustentabilidad de la estrategia vigente: Una nota de alerta}

A pesar que Chile se ha inscrito entre las economías más dinámicas del mundo en los últimos 20 años, una señal de alerta aparece al comparar la estrategia vigente en Chile con la implementada por los países más desarrollados —esto es, con las políticas implementadas en aquellas naciones con un PIB por habitante medido a PPC mayor a US\$20.000 por año. En particular se verifica que estos países son en promedio mucho menos dependientes de sus recursos naturales (contrastar Gráficos $\mathrm{N}^{\circ} 2$ y $\mathrm{N}^{\circ} 3$ ). En efecto, en Chile el $85 \%$ de las exportaciones corresponde a productos primarios o manufacturas basadas en recursos naturales, mientras que en los países más desarrollados estos productos representan menos del $25 \%$ de sus exportaciones.

Otra diferencia notoria con estos países más desarrollados es nuestra muy deficiente distribución del ingreso. Por ejemplo, la relación entre el ingreso captado por el $10 \%$ más rico de la población y el $10 \%$ más pobre es 4 veces mayor en Chile que en el promedio de los países desarrollados. Incluso, es al menos 2 veces mayor que el país con la peor distribución de ingreso de dicho grupo.

Todo lo anterior lleva a reflexionar respecto a si la estrategia chilena permitirá alcanzar dicho nivel de desarrollo y equidad, o si por el contrario, ya se podría estar alcanzando un techo de inferior nivel. Esto pone de manifiesto la importancia de analizar la sustentabilidad de la estrategia de crecimiento vigente. En particular, dado que el objetivo explícito de la estrategia aplicada desde 1990 consiste en crecer más y distribuir mejor, 
GRÁFICO N ${ }^{\circ}$ 3: $\quad$ COMPOSICIÓN DE EXPORTACIONES DE PAÍSES CON PIB POR HABITANTE PPC MAYOR A US\$20.000 POR AÑO, 2002

(\% total de exportaciones)

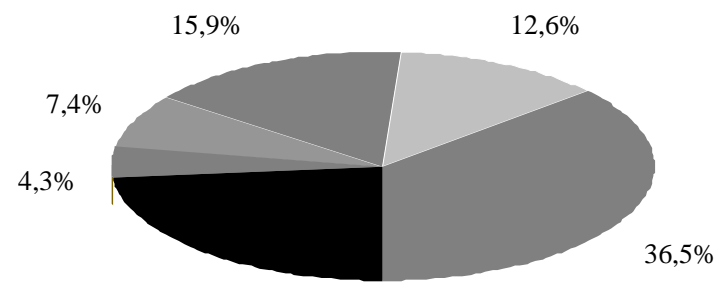

$23,3 \%$

$\square$ Productos primarios
$\square$ Manufacturas basadas en RRNN
$\square$ Manufacturas de baja tecnología
$\square$ Manufacturas de media tecnología
Manufacturas de alta tecnología
$\square$ Otras transacciones

Fuente: Elaborado por los autores sobre la base de estadísticas CEPAL.

debe haber preocupación por la sustentabilidad de estos dos elementos. Así, por una parte deben evaluarse las limitantes al crecimiento propiamente tal, mientras que, por otra, deben considerarse las limitantes a que tal crecimiento, en el caso de materializarse, beneficie equitativamente a los distintos estratos de la sociedad. Entre las primeras debe considerarse que:

- Las ventajas comparativas estáticas son vulnerables. Existen países a) con abundantes dotaciones de los mismos recursos que Chile, y/o b) que tienen mayor escala y mano de obra semi-calificada más abundante y barata, y/o c) que están más cerca de los centros de consumo. Estos países pueden quitarle a Chile una parte importante de sus mercados. Esta amenaza se hace más real a medida que dichos países van abriendo su economía al exterior y van realizando las reformas pro-mercado que Chile ya efectuó.

Las ventajas comparativas en recursos naturales son vulnerables. En primer lugar, existe el riesgo de agotamiento paulatino de aquellos recursos no renovables. Adicionalmente, los avances en biotecnología potencialmente relativizan las ventajas comparativas dadas por la abundancia de recursos naturales.

El impulso de crecimiento de las reformas pro-mercado tiende a agotarse. Las reformas del tipo "Consenso de Washington" en Latinoamérica, de las cuales Chile fue un pionero, han generado creci- 
miento. Sin embargo, en general éste ha sido menor al esperado, tanto en tamaño como en duración, evidenciándose una pérdida de impulso de las reformas ${ }^{9}$. Así, hay numerosos ejemplos, como los casos de México y El Salvador, donde se observa que la macroeconomía en orden es condición necesaria, pero no suficiente, para un crecimiento sostenido.

- Existe convergencia condicional en tasas de crecimiento. La evidencia muestra que a medida que un país se desarrolla aceleradamente, su tasa de crecimiento tiende a converger a aquella más lenta de los países avanzados. Esta convergencia es empero condicional, entre otras cosas, al cambio tecnológico experimentado por el país en comparación al experimentado por los países líderes ${ }^{10}$. Así, dada esta condicionalidad, si Chile presenta rezagos en innovación convergerá hacia tasas de crecimiento más bajas.

En cuanto a las limitantes para avanzar en términos de equidad, se distinguen principalmente dos: a) la eventual ausencia de crecimiento, y b) una modalidad de crecimiento en el cual no haya consistencia entre oferta y demanda por capital humano.

La eventual ausencia de crecimiento, que puede ocurrir por cualquiera de los límites al crecimiento antes mencionados, desafía el logro de la equidad por dos vías. Primero, un menor crecimiento disminuye las oportunidades de desarrollo que los individuos pueden aprovechar en forma autónoma. Y segundo, limita la capacidad del Estado para mejorar la distribución del ingreso a través del financiamiento de una red de protección social adecuada para los segmentos más carentes de la población y de la provisión de los bienes públicos necesarios para aumentar su capacidad productiva — como justicia, infraestructura, seguridad, educación, salud, y capacidad innovadora. Esto último, por cuanto el gasto público está acotado en el corto plazo por la capacidad de recaudación tributaria, que a su vez depende de la carga tributaria y del nivel de producto. Considerando que en Chile la carga tributaria ya se encuentra alineada con su nivel de ingreso (y en ningún caso puede ser calificada de excesiva, ya que como muestra el Gráfico $\mathrm{N}^{\circ} 4$ no existen países que tengan a la vez un ingreso mayor y una carga tributaria menor que el nuestro), es el nivel de producto el que determina la capacidad de gasto público ${ }^{11}$.

${ }^{9}$ Para un mayor detalle, véase Lora y Panizza (2002).

${ }^{10}$ Para un mayor detalle, véase Bloom et al. (2002).

${ }^{11}$ Con todo, en el corto plazo se requiere continuar mejorando la eficiencia y la focalización del gasto público. Y, a la vez, reforzar las medidas para disminuir la elusión y la evasión tributaria, condición necesaria para que en el mediano y largo plazo la carga tributaria aumente como efecto del mismo crecimiento. 
GRÁFICO N ${ }^{\circ}$ 4: CARGA TRIBUTARIA SEGÚN PIB POR HABITANTE PPC, COMPARACIÓN INTERNACIONAL, 2000 (1)

(US\$ PPC; \% del PIB [eje horizontal])

PIB por habitante

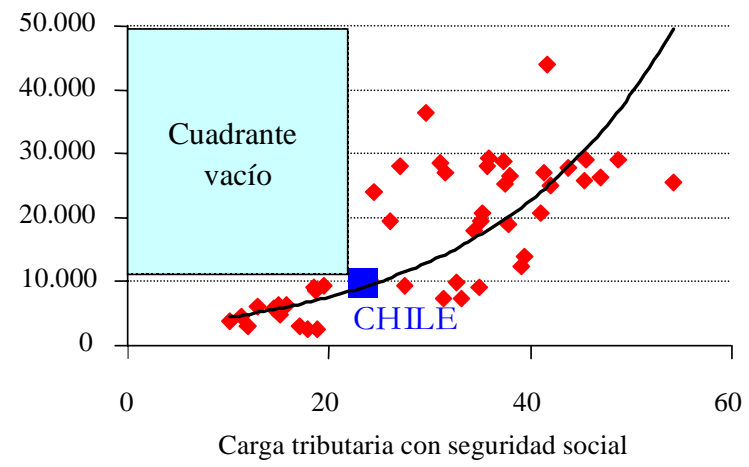

(1) Considera carga tributaria de todo el sector público (para hacer las cifras comparables, para los casos de Argentina, Chile y Singapur se agregan las cotizaciones obligatorias para seguridad social administradas por el sector privado). el FMI.

Fuente: Elaborado por los autores sobre la base de información del Banco Mundial y

La segunda gran amenaza a poder seguir avanzando en equidad no se refiere a la ausencia de crecimiento, sino que al tipo de crecimiento que el país es capaz de generar. En particular, una estrategia de crecimiento que no procura explícitamente avanzar en el nivel y consistencia de la oferta y demanda por capital humano, corre el riesgo de no avanzar en equidad. Concretamente, dado que la principal causa de las desigualdades de ingreso autónomo es la desigual distribución del capital humano, se hace imprescindible mejorar esta última distribución mediante inversiones en capital humano. Sin embargo, si no existe una demanda por este capital humano de mayor calidad por parte del sector productivo nacional, puede ser más rentable ofrecer las habilidades laborales en el exterior ("fuga de cerebros") desaprovechando el país la inversión realizada y no provocando mejoras en la distribución de ingresos interna. Incluso, puede generarse "cesantía ilustrada", desaprovechando social e individualmente la inversión, lo que eventualmente puede desalentar el esfuerzo individual de invertir en educación. En este sentido, la evidencia muestra que los países que no han sincronizado sus esfuerzos en cerrar sus brechas en educación y en tecnología - esta última como motor de la demanda privada por capital 
humano- no han experimentado crecimientos significativos de productividad ni mejoras de equidad. Incluso, si el país presenta una desigual distribución de capital humano inicial, como es el caso de Chile, y se avanza sólo en progreso tecnológico, se corre el riesgo de exacerbar las desigualdades de ingreso al aumentar el premio por capital humano.

\section{Superando los límites: \\ La economía del conocimiento en torno a los recursos naturales}

\subsection{Los recursos naturales como oportunidad}

Ante las amenazas a la sustentabilidad de la estrategia de crecimiento chilena, cabe preguntarse si existe tal cosa como una "maldición" de los recursos naturales que impida crecer sostenidamente a tasas altas. La pregunta no es baladí, pues existe evidencia en ese sentido. Por ejemplo, Sachs y Warner (1995) encuentran una relación negativa entre crecimiento económico y exportaciones de recursos naturales como porcentaje del PIB. En particular, estiman que un incremento de diez puntos porcentuales en las exportaciones de recursos naturales como porcentaje del PIB implica una menor tasa de crecimiento de alrededor de 0,7 puntos porcentuales por año. Este efecto de desaceleración del crecimiento puede deberse, según estos autores, a tres fenómenos diferentes, aunque potencialmente simultáneos. En primer lugar, a un fenómeno social, mediante el cual la abundancia llevaría a la pereza de la población. En segundo lugar, a un fenómeno de economía política, mediante el cual esta abundancia generaría ineficiencias por incentivar el desvío de esfuerzos y recursos a la búsqueda de rentas $^{12}$. Y en tercer lugar, a un fenómeno económico conocido como la "enfermedad holandesa", a través del cual la abundancia de recursos naturales tendería a apreciar la moneda local, disminuyendo la competitividad de las manufacturas, desviando recursos desde el sector industrial hacia el de recursos naturales ${ }^{13}$.

${ }^{12}$ La constante presión por un "dólar alto", así como por reducir ulteriormente la ya moderada carga tributaria, es sin duda una clara manifestación de este fenómeno en nuestro país.

${ }^{13}$ Con todo, el fenómeno de la "enfermedad holandesa" sólo se traduciría en un menor crecimiento si la productividad en el sector manufacturero fuese mayor que en el resto de la economía. Este puede ser el caso si a) el sector manufacturero genera mayores encadenamientos productivos que la explotación de recursos naturales (modelo presentado por Hirschman, 1958); y/o b) el sector manufacturero genera mayores economías dinámicas, por ejemplo, mediante un mayor "learning-by-doing" (modelo presentado por Matsuyama, 1992). 
Sobre la base de la evidencia agregada presentada por Sachs y Warner (1995) y observando la composición actual de las exportaciones de los países más desarrollados (Gráfico $\mathrm{N}^{\circ} 3$ ) podría concluirse, equivocadamente, que la estrategia de desarrollo a seguir debiese ser una industrialización forzada. Sin embargo, alejarnos de nuestras ventajas comparativas en recursos naturales equivaldría a volver a cometer errores pasados de desarrollo frustrado. En este sentido son iluminadores los casos de países ricos en recursos naturales, entre ellos Finlandia, Suecia, Australia y Nueva Zelanda, que sí han logrado desarrollarse en forma permanente y acelerada, justamente aprovechando esta condición de abundancia. Como se aprecia en el Gráfico $\mathrm{N}^{\circ}$ 5, existe un subconjunto de países desarrollados, con abundancia de recursos naturales, para los cuales las materias primas y las manufacturas basadas en éstas siguen teniendo una participación significativa en su economía - aunque de todas maneras mucho menor que la que tienen en Chile. Asimismo, también existen casos de sectores primarios que han evidenciado aumentos acelerados de productividad, incluso por sobre el sector manufacturero ${ }^{14}$. Lo importante es entonces entender cómo
GRÁFICO N ${ }^{\circ}$ 5: $\quad$ PARTICIPACIÓN DE RECURSOS NATURALES EN EXPORTACIONES, CHILE Y PAÍSES DESARROLLADOS (CON PIB POR HABITANTE PPC MAYOR A US\$20.000), 2002
(\% total de exportaciones)

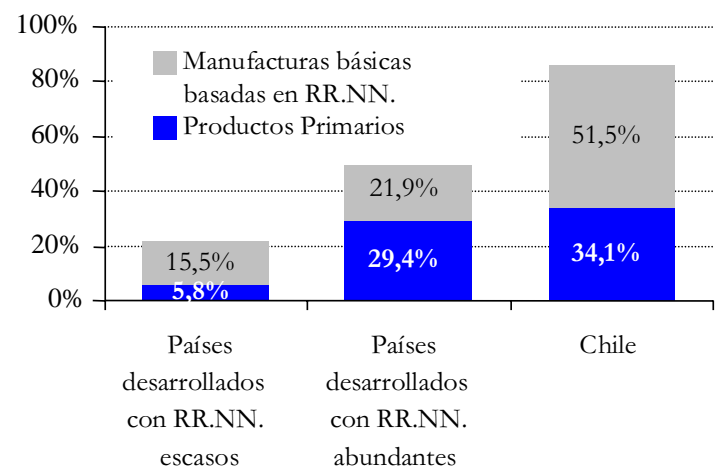

Fuente: Elaborado por los autores sobre la base de estadísticas CEPAL.

${ }^{14}$ Por ejemplo, Martin y Mitra (2001) muestran que el crecimiento de la productividad total de factores del sector agrícola en el período 1967-1992 fue superior a la del sector industrial, tanto para los países en desarrollo, como para los industrializados. Por su parte, De Ferranti et al. (2002) proveen evidencia de este fenómeno en otros sectores primarios, como el minero, el frutícola y el forestal. 
estos países —o sectores específicos, según el caso- transformaron la supuesta "maldición" de los recursos naturales en una oportunidad o "bendición” y, por lo tanto, qué es lo que puede y debe hacer Chile para seguir este camino.

Un punto de partida para este análisis es examinar el rol del capital humano y su interacción con la disponibilidad de recursos naturales (De Ferranti et al., 2003). En este sentido, Bravo-Ortega y De Gregorio (2004) muestran que la abundancia de recursos naturales afecta negativamente el crecimiento económico, pero sólo en aquellos países con bajos niveles de capital humano. Así, aquellos países con abundante capital humano podrían desarrollar conjuntamente sus sectores primarios y manufactureros y crecer a tasas aceleradas. Esto último es lo que explicaría la diferencia en crecimiento experimentada en el siglo XX por los países escandinavos en contraste con los latinoamericanos, ambos con niveles similares tanto de PIB por habitante como en intensidad en recursos naturales hace un siglo ${ }^{15}$, pero con dramáticas diferencias de capital humano "inicial" en favor de los primeros $^{16}$.

Construyendo sobre su disponibilidad de capital humano, un segundo elemento que se destaca en la estrategia de los países ricos en recursos naturales que han logrado desarrollarse es ciertamente su capacidad de innovación, definida en términos amplios como el proceso colectivo continuo, complejo e incierto, mediante el cual las empresas crean, adaptan o adoptan tecnologías con el fin de cimentar sus ventajas competitivas ${ }^{17}$. En este sentido debe destacarse la importancia de adaptar y adoptar, pues puede ser una fuente más eficiente de innovación, especialmente para países rezagados respecto a la frontera del conocimiento ${ }^{18}$. De todas maneras, en los sectores en que Chile es líder mundial, sí se hace necesario invertir en expandir la frontera del conocimiento, pues puede no haber alguien a quien copiarle.

El proceso de innovación es colectivo, por cuanto las innovaciones surgen tanto de las relaciones intra-empresa, como extra-empresa con

${ }^{15}$ A modo de ejemplo, en 1870 el PIB por habitante de Finlandia era 0,96 veces el de Chile, mientras que en 1990 equivalía a 2,60 veces éste (cifras presentadas por Bravo-Ortega y De Gregorio, 2004).

${ }^{16}$ A fines del siglo XIX la tasa de alfabetización en los países escandinavos era de al menos $89 \%$, mientras que en Latinoamérica la mayor era la de Argentina con un $46 \%$, seguida por la de Chile con un 30\% (cifras presentadas en Bravo-Ortega y De Gregorio, 2004). Diferencias significativas se mantienen hoy cuando se analizan indicadores de calidad educacional (véase sección 4).

${ }^{17}$ Definición basada en Georghiou et al. (2003).

18 Adaptar y adoptar es también clave en los países desarrollados. Por ejemplo, se estima que el $86 \%$ del progreso tecnológico en Francia se basa en tecnologías extranjeras, mientras que en EE.UU. los recursos destinados a adoptar tecnologías externas son 30 veces los dedicados a innovar en la frontera del conocimiento (De Ferranti et al., 2003). 
agentes externos, tales como universidades, centros de investigación, agencias públicas, consumidores, proveedores, e incluso competidores. Es continuo, por cuanto las innovaciones suelen basarse en sucesivas retroalimentaciones entre los diferentes agentes, a través de las cuales las capacidades y habilidades para innovar se desarrollan de manera acumulativa —más aún, la principal fuente de innovación no suele ser la investigación pura, sino que la práctica cotidiana que identifica oportunidades de mejoras. Es complejo, por cuanto el proceso implica la interacción de agentes internos y externos, que difieren, al menos, en capacidades e información disponible, lo que aumenta los costos de transacción. Y es incierto, pues por definición los resultados del proceso innovador pueden no ser exitosos.

El esfuerzo innovador de los países bajo análisis queda de manifiesto, por ejemplo, en el gasto en Investigación y Desarrollo - que alcanza a 3,4\% del PIB en Finlandia y 4,3\% en Suecia, versus sólo 0,7\% en Chile—, y en el número de patentes producidas al año — que alcanza a 180 por cada millón de habitantes en Finlandia y 195 en Suecia, versus sólo 1 en Chile.

Este esfuerzo innovador se ha focalizado en estos países precisamente alrededor de sus recursos naturales abundantes. Esto contrasta con lo que sucedió en Chile - y en Latinoamérica en general — hasta mediados de la década del 70; mientras en Chile se intentaba una industrialización forzada inconsistente con nuestras ventajas comparativas, en países como los escandinavos y también en Australia, Nueva Zelanda y Canadá, entre otros, el crecimiento se basaba en ellas, desarrollándose encadenamientos productivos hacia atrás, adelante y los costados (Blomstrom y Meller, 1991). De esta manera, en los países ricos en recursos naturales hoy desarrollados, han surgido complejos productivos o "clusters" en torno a ellos ${ }^{19}$. Por "cluster" se entiende "una concentración sectorial y/o geográfica de empresas que se desempeñan en las mismas actividades o en actividades estrechamente relacionadas - tanto hacia atrás, hacia los proveedores de insumos y equipos, como hacia adelante y hacia los lados, hacia industrias procesadoras y usuarias así como a servicios y actividades estrechamente relacionadas - con importantes y cumulativas economías externas, de aglomeración y de especialización, y con la posibilidad de llevar a cabo una acción conjunta en búsqueda de eficiencia colectiva"20.

19 Son relevantes, entre muchos otros, el cluster en torno a la actividad marítima en Noruega, en torno a la producción y comercialización de flores en Holanda, en torno al sector lácteo-ganadero en Dinamarca, y los clusters mineros en Australia, Canadá y Finlandia — caso particularmente interesante, puesto que el sector sobrevive de manera activa a pesar que la extracción minera propiamente tal es ya poco importante.

${ }^{20}$ Definición dada por Ramos (1999). Otros autores, como Alternburg y MeyerStamer (1999) y Schmitz (1995), resaltan que si bien la definición básica de "cluster" está 
Estos "clusters" han surgido principalmente de la evolución natural de las fuerzas del mercado ${ }^{21}$, con el fin de aprovechar lo que en la literatura se conoce como "externalidades locales específicas a la industria"22. Con todo, el Estado sí ha contribuido a solucionar las fallas de mercado que dificultan o hacen más lenta su evolución a la madurez, principalmente aquellas asociadas a las asimetrías de información y costos de transacción. Para ello ha provisto infraestructura y ha construido capital social (dado por la confianza basada en instituciones, tanto formales como informales), ambos necesarios para la interacción eficiente de los agentes económicos. Otro aporte fundamental del Estado ha sido su rol en la formación del capital humano requerido para innovar en torno a los "clusters".

Finalmente, un tercer elemento presente en los países intensivos en recursos naturales que han sido exitosos en desarrollarse, es el marco dado por su régimen institucional y de incentivos económicos. Éste considera, en primer lugar, la estabilidad macroeconómica necesaria para estimular las inversiones, reduciendo la volatilidad de precios relativos. En segundo lugar, claridad en las reglas del juego, principalmente en lo referido a los derechos de propiedad y primacía de contratos, claves para incentivar el proceso innovador y su difusión. Y en tercer lugar, el adecuado funcionamiento y desarrollo del mercado de capitales, necesario para el financiamiento del emprendimiento innovador ${ }^{23}$. En todos estos aspectos, países como los escandinavos se han destacado históricamente ${ }^{24}$.

dada por la mera aglomeración geográfica de ciertas actividades económicas, su atractivo en términos de políticas públicas se refiere a la posibilidad de alcanzar eficiencia colectiva en ellos.

${ }^{21}$ En la literatura se identifican distintas etapas en la evolución de los complejos productivos exitosos. El caso del cluster forestal en Finlandia (descrito en Ramos (1999) y Palmberg (2004)) las ejemplifica claramente. Hacia finales del siglo XIX y principios del XX, se extraía y exportaba principalmente productos primarios y algunos con poca elaboración, importándose la mayoría de los insumos, maquinaria e ingeniería. A partir de 1920 surgió el procesamiento y exportación de pulpa, cartón y papel, sustituyéndose además localmente algunos insumos, equipos y servicios de ingeniería. A partir de 1960 se comenzó a exportar maquinaria a la Unión Soviética, los servicios de ingeniería se volvieron completamente locales y se profundizó la exportación de productos más sofisticados, como papeles finos. Finalmente, a partir de 1970 comenzaron las exportaciones de productos químicos y servicios de ingeniería, se profundizó la exportación de maquinaria a mercados más exigentes, e incluso las empresas locales comenzaron a invertir en estos rubros en el exterior.

${ }^{22}$ Para mayores detalles, véase Krugman (1991) y Rodríguez-Clare (2004).

${ }^{23}$ Indicadores del Banco Mundial (http://info.worldbank.org.etools/kam2004) sitúan a Finlandia y Suecia entre los cinco países con mayor disponibilidad de capital de riesgo.

24 En el Índice 2004 de Competitividad para el Crecimiento del World Economic Forum, Finlandia, Dinamarca y Noruega están entre los cinco primeros lugares, tanto en el componente de "ambiente macroeconómico", como en el componente de "instituciones públicas". 
En resumen, la experiencia de países exitosos indica que los recursos naturales están lejos de ser una maldición. Por cierto, países escasos en ellos, como Japón y Corea del Sur, han optado por una estrategia de exportaciones de manufacturas, primero intensivas en mano de obra y luego más sofisticadas. Sin embargo, los países exitosos abundantes en recursos naturales han optado por una industrialización en torno a estos recursos, demostrando que existen caminos alternativos para lograr el éxito. Para ello han enfatizado tres elementos: (i) un régimen institucional y de incentivos económicos claro, coherente y estable; (ii) una fuerte capacidad de innovación, orientada a desarrollar encadenamientos productivos en torno a ventajas comparativas; y (iii) un capital humano de calidad.

Así, un buen o mal desempeño de los países con abundantes materias primas, como lo es Chile, depende crucialmente de la congruencia de su política de desarrollo y no del hecho mismo de tener recursos primarios. Por lo tanto, importa más el cómo se produce, y no tanto el sector donde se haga, siempre y cuando existan ventajas comparativas para sustentarlo ${ }^{25}$.

En el caso de Chile, una política de desarrollo que se construya sobre la base de sus ventajas comparativas en recursos naturales; que sea capaz de construir pilares sólidos de capacidad innovativa y capital humano en un marco institucional y económico estable; y que aproveche las potencialidades de los clusters que incipientemente están surgiendo en torno a los sectores primarios, aparece como la alternativa más viable para superar las limitaciones del modelo vigente. Esta alternativa, como muestra la experiencia internacional, es además realizable en un período relativamente corto $^{26}$.

\subsection{Fortalezas y debilidades de Chile para implementar la estrategia}

Ciertamente, los tres elementos identificados como claves para implementar la economía del conocimiento están interrelacionados unos con otros. Este es un punto crucial, pues la ausencia de uno de ellos basta para

${ }^{25}$ Es razonable argumentar que existe una competencia significativa de países que sí tienen ventajas comparativas en el desarrollo de manufacturas no intensivas en recursos naturales, incluyendo a China e India, contra los cuales es poco probable que Chile pueda salir airoso.

${ }^{26}$ Por ejemplo, Finlandia pasó de invertir sólo el 1,6\% de su PIB en investigación y desarrollo en 1985, a 3,4\% quince años más tarde. Asimismo, en similar período sus exportaciones tecnológicas como porcentaje de sus exportaciones totales pasaron de representar menos del $6 \%$ a representar más del $25 \%$. 
que el conjunto no funcione ${ }^{27}$. En efecto, en ausencia de un régimen institucional claro, coherente y estable, es improbable que existan incentivos fuertes para invertir en el sector productivo, en actividades innovativas y en capital humano. Por otra parte, sin una demanda por capital humano de mayor calidad por parte del sector productivo no resulta rentable invertir en la oferta del mismo; y viceversa, sin una oferta de capital humano calificado la capacidad innovativa del sector productivo se ve limitada. Finalmente, una industrialización forzada, inconsistente con las ventajas comparativas, haría a la larga insostenibles los esfuerzos en materia de innovación y capital humano.

La necesidad de cerrar las brechas en capital humano y capacidad de innovación de manera sincronizada resulta particularmente crítica ${ }^{28}$. La necesidad de capital humano de calidad para el desarrollo innovador se sustenta en tres elementos. Primero, se requieren trabajadores debidamente capacitados en el sentido de ser flexibles para implementar nuevas tecnologías y adaptarse a los cambios. Segundo, las tecnologías factibles de ser adoptadas y/o adaptadas desde los países desarrollados tienden a ser intensivas en mano de obra calificada, pues éstas generalmente son consistentes con la calidad de la mano de obra en su país de origen. Y tercero, para el proceso mismo de adoptar y adaptar las tecnologías externas se requiere mano de obra calificada. Por su parte, la necesidad de desarrollar la capacidad innovadora del país para sustentar una mejora de su capital humano se basa en que la rentabilidad de la educación es función de las tecnologías disponibles en el país. Así, ante la ausencia de progreso tecnológico puede no ser rentable invertir en educación, o puede ser más rentable ofrecer las habilidades laborales en el exterior, produciéndose una migración de capital humano. La evidencia empírica muestra que los países que no han sincronizado sus esfuerzos en cerrar estas dos brechas no han sido capaces de experimentar crecimientos significativos de productividad ${ }^{29}$. Incluso, si el país presenta una desigual distribución de capital humano y se avanza sólo en progreso tecnológico, se corre el riesgo de exacerbar las desigualdades de ingreso (como muestra Acemoglu, 1998) y, peor aún, estancar el desarrollo por la falta de competencias laborales suficientes para innovar.

Existen diferentes instrumentos para evaluar la posición de Chile en cada uno de los pilares identificados. Una primera aproximación la da el

${ }^{27}$ Por ejemplo, las otrora denominadas economías socialistas fallaban en dos de estos tres pilares, pues si bien enfatizaban el desarrollo de capital humano, carecían de incentivos para la producción eficiente y para la innovación. De otra parte, el mero "Consenso de Washington" también resultó ser incompleto, respecto al desarrollo de capital humano y el fomento a la innovación.

${ }^{28}$ Para mayor detalle, véase De Ferranti et al. (2003).

${ }^{29}$ Para mayor detalle sobre esta evidencia, véase Gill (2003). 
Índice de Competitividad para el Crecimiento del World Economic Forum. Para el índice 2004 Chile se destaca en las áreas de instituciones públicas (lugar 20 en el mundo) y ambiente macroeconómico (lugar 27), estando más rezagado en el ámbito tecnológico (lugar 32), especialmente en lo referido a innovación (lugar 36).

El modelo desarrollado por el Banco Mundial para diagnosticar cuán preparado está cada país para seguir el camino de la economía del conocimiento (World Bank, 2004) genera conclusiones similares. Como se observa en el Gráfico $\mathrm{N}^{\circ} 6^{30}$, Chile presenta un rendimiento destacado,

GRÁFICO N 6: POSICIÓN RELATIVA DE CHILE RESPECTO A PAÍSES EMERGENTES + OCDE EN VARIABLES CLAVES DE LA ECONOMÍA DEL CONOCIMIENTO. DATOS 2003 O MÁS RECIENTES

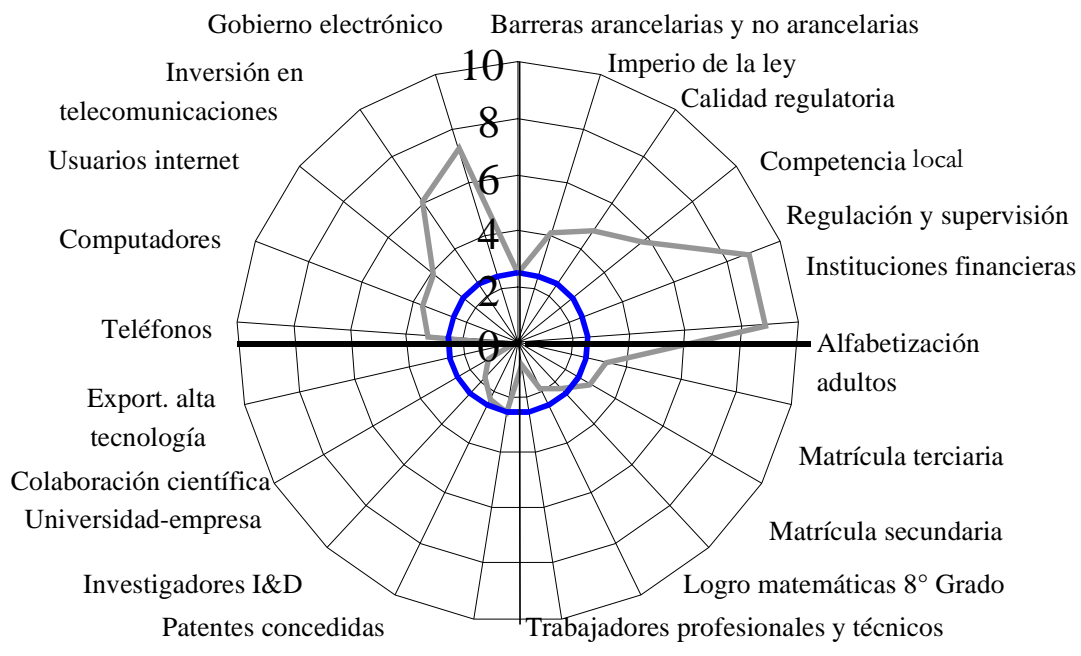

Artículos técnicos y científicos

Fuente: Elaborado por los autores sobre la base de los indicadores KAM del Banco Mundial (http://info.worldbank.org.etools/kam2004).

${ }^{30}$ El Gráfico $\mathrm{N}^{\circ} 6$ presenta la posición relativa de Chile en una serie de variables, respecto al conjunto constituido por los países emergentes más los pertenecientes a la OCDE. Mientras más alejada esté una observación del centro del gráfico, mejor es la posición relativa del país. Como referencia se incluye la posición relativa de Chile en términos de PIB por habitante PPC (indicada por la circunferencia más oscura), la que permite identificar si para una determinada variable el país está rindiendo por sobre o bajo lo esperado dado su nivel de ingreso. Por ejemplo, en el ámbito de "regulación y supervisión de instituciones financieras", nuestro país se ubica en el percentil 88 , lo que está muy por encima del percentil en el que se ubica nuestro PIB por habitante (percentil 25). 
muy por sobre lo esperado dado su nivel de ingreso, en todas aquellas dimensiones relacionadas con el "régimen económico y de incentivos" (cuadrante superior derecho). En particular, destacan aspectos como la regulación y supervisión del sector financiero, la intensidad de competencia en los mercados locales, la calidad regulatoria y el imperio de la ley. Para su nivel de ingreso, Chile también presenta un rendimiento destacado en aquellas dimensiones relacionadas con la "infraestructura pro innovación" (cuadrante superior izquierdo), como por ejemplo el desarrollo del e-government, la inversión en telecomunicaciones, e incluso, en usuarios de computadores e internet.

En contraste, el país presenta un rendimiento inferior al esperado en todas las dimensiones asociadas a "capacidad innovativa" (cuadrante inferior izquierdo) y en prácticamente todas las variables relacionadas a "capital humano" (cuadrante inferior derecho). En particular, en el primero de estos ámbitos Chile exhibe una bajísima proporción de exportaciones tecnológicas, un bajo grado de colaboración científica entre universidades y empresas, y un bajo esfuerzo en investigación y desarrollo, así como en patentamiento. En este ámbito sólo la publicación de artículos técnicos y científicos está en línea con el nivel de ingreso de Chile. En el ámbito de "capital humano", Chile está particularmente rezagado en disponibilidad de trabajadores profesionales y técnicos, así como en logro en matemáticas en el nivel básico.

En resumen, para seguir el camino de los países que han logrado desarrollarse aplicando la economía del conocimiento a sus recursos naturales, Chile debe concentrar sus esfuerzos, simultáneamente, en incrementar su capacidad de innovación - materia que se analiza en detalle en la Sección 3- y en mejorar la calidad de su capital humano - materia que se desarrolla en la Sección 4. Dadas las interrelaciones que existen entre los distintos pilares de la economía del conocimiento, las estrategias a seguir en estas dos áreas deben ser consistentes con el desarrollo de encadenamientos productivos en torno a las ventajas comparativas del país, y no erosionar su régimen institucional y de incentivos económicos que actualmente constituye la base desde la cual podemos dar los pasos siguientes.

\section{Capacidad de innovación}

La experiencia de los países líderes en innovación insinúa que ésta, construida sobre la base de un capital humano calificado y en un contexto de incentivos económicos adecuados, ha tenido un efecto positivo en el crecimiento económico. Más allá del estudio de casos puntuales, la evidencia empírica muestra que existe una relación positiva entre el gasto en 
investigación y desarrollo y la productividad total de factores, aunque con rezagos (véase Rouvien, 2002, para el caso de los países de la OCDE). Consistentemente, para el caso de Chile, Benavente (2004b) encuentra que aumentos en el esfuerzo en investigación y desarrollo traerían importantes incrementos en la tasa de crecimiento del producto. Así, dado que el esfuerzo innovador es deseable para el desarrollo, cabe preguntarse si existe un rol para el Estado en el ámbito de las políticas pro innovación.

\subsection{La innovación como un ámbito de políticas públicas}

Las políticas pro innovación constituyen necesariamente parte del ámbito de políticas públicas, en el sentido que existe un rol para el Estado que no puede ser reemplazado por las fuerzas del mercado. Esto marca una profunda diferencia con otras políticas usualmente propuestas como supuestamente aceleradoras del crecimiento económico, entre las que se cuentan los incentivos para fomentar la inversión extranjera directa ${ }^{31}$, promocionar las exportaciones ${ }^{32}$, y apoyar la supervivencia de las PYME $^{33}$.

La justificación económica de las políticas de promoción de la innovación puede clasificarse en dos áreas ${ }^{34}$ : (i) la existencia de fallas de mer-

${ }^{31}$ Se argumenta que la inversión extranjera directa podría generar encadenamientos productivos y transferencias tecnológicas. Sin embargo, la evidencia no es concluyente al respecto, especialmente cuando el país tiene bajo capital humano. Para una revisión de esta evidencia, véase Alfaro y Rodríguez-Clare (2003). Además, si lo que interesa son los encadenamientos y las transferencias tecnológicas, éstos debiesen ser promocionados directamente.

${ }^{32}$ La hipótesis detrás de la promoción de exportaciones es que el acto de exportar aumentaría la productividad de las empresas. Sin embargo, la evidencia muestra que la causalidad es inversa, es decir, son las empresas con mayor crecimiento de productividad las que tienden a exportar (Para mayor detalle, véase Álvarez, 2004 y Rodrik, 1995).

${ }^{33}$ Desde el punto de vista de la productividad total de la economía, el tener políticas generales destinadas a garantizar la supervivencia de las PYME más allá de su viabilidad económica resulta contraproducente. Esto es así por cuanto estas políticas inhiben una fuente clave de crecimiento que es la búsqueda de eficiencia a través de la destrucción creativa que implica la prueba y error en los procesos de formación, muerte y reemplazo de proyectos y empresas. Otro argumento en contra de las políticas generales de apoyo a las PYME es que esta categorización esconde una gran heterogeneidad, incluyendo empresas con potencial de crecimiento, otras para las cuales la escala de operación eficiente es precisamente pequeña, y otras destinadas a desaparecer por su baja productividad (Di Tommaso y Dubbini, 2000). En consecuencia, la racionalidad respecto a las PYME debiese ser corregir las fallas de mercado que las afectan directamente donde éstas ocurren, como por ejemplo en el mercado del crédito y en el mercado de transferencia tecnológica y asociatividad. Para mayores detalles respecto a las fallas de mercado que afectan a las PYME, véase Rodríguez-Clare (2004), Benavente y Crespi (2002), Hallberg (2000) y Stiglitz (1993).

${ }^{34}$ Eventualmente se considera una tercera justificación, referida a la innovación en el contexto de modelos de crecimiento endógeno. En estos modelos se asume que las inversiones en innovaciones tecnológicas presentan rendimientos crecientes y, por lo tanto, aumentan la tasa de crecimiento de estado estacionario (al respecto, véase Romer, 1990). Con todo, la evidencia no es concluyente al respecto. 
cado asociadas al fenómeno innovador, incluyendo aquellas asociadas al financiamiento del emprendimiento innovador; y (ii) la existencia de fallas sistémicas asociadas al proceso innovador.

Dentro de las fallas de mercado asociadas al fenómeno innovador destacan ${ }^{35}$ :

- Insuficiente apropiabilidad de beneficios. Dado que el conocimiento tiene carácter de bien público, en el sentido de ser su consumo no rival y sólo parcialmente excluible, se produce un desincentivo a invertir en su generación, y un incentivo a esperar aprovechar el conocimiento generado por otros sin incurrir en los altos costos que implica su generación. El grado en que se manifieste esta falla dependerá de cómo se definan y protejan los derechos de propiedad de las innovaciones.

- Asimetrías de información, altos costos de transacción y de coordinación. Muchos proyectos innovadores pueden beneficiar a varios agentes, a una industria completa o incluso a varias industrias. Más aún, pueden ser rentables sólo si cuentan con una escala suficiente. El problema surge cuando por asimetrías de información, altos costos de transacción y desconfianzas, no se produce la coordinación necesaria entre los agentes, y se termina por duplicar esfuerzos o simplemente no emprender la innovación.

- Externalidades de red. Estas externalidades ocurren cuando el valor de un bien para un agente se incrementa mientras más agentes consuman dicho bien. Esto ocurre con muchas innovaciones tecnológicas, como por ejemplo en telecomunicaciones, donde un nuevo sistema de telefonía sólo tiene valor si es útil para comunicarse con los demás. Los costos de transacción y coordinación pueden dificultar que se alcance la masa crítica requerida para rentabilizar privadamente una innovación con estas características.

- Alta incertidumbre no cuantificable, intangibilidad de los activos y mercados financieros incompletos. Muchos proyectos innovadores pueden no alcanzar un desarrollo comercial o pueden llevar a un resultado muy distinto al esperado. Esta incertidumbre suele ser difícil de cuantificar, y por lo mismo, suele no contar con financiamiento privado a través de los mecanismos tradicionales de mercado. Esto resulta aún más complejo si se considera que en general los activos de este tipo de proyectos son intangibles. Adicionalmente, en los proyectos innovadores se generan importantes asimetrías de información, que surgen porque quienes los operan o administran

${ }^{35}$ Para mayor detalle, véase Georghiou et al. (2003), y Benavente (2004a). 
manejan un nivel de información muy superior a quienes los financian, lo que puede dar lugar a comportamientos oportunistas que elevan los niveles de riesgo de estas inversiones. Todo esto disminuye aún más las posibilidades de financiamiento privado tradicio$\mathrm{nal}^{36}$.

Por su parte, la visión sistémica de la innovación se refiere a que ésta surge de un proceso no lineal, que envuelve no sólo a la investigación, sino que también a un complejo proceso de actividades relacionadas como capacitación, diseño y financiamiento, entre otras. Esta visión reconoce además que las empresas no innovan de manera aislada, sino que lo hacen al relacionarse con universidades, centros de investigación, agencias públicas, proveedores, clientes, y sus propios competidores. Para un resultado exitoso, se requiere entonces una interacción entre las capacidades internas de la empresa, con las de los agentes que la rodean. El espacio para las políticas públicas que surge de esta visión — que en todo caso no se contradice con la visión tradicional de las fallas de mercado-, se refiere en particular a: la provisión de infraestructura para que el sistema opere; la determinación de la institucionalidad para que las transacciones ocurran de manera expedita y eficiente — por ejemplo en lo referido a los derechos de propiedad de innovaciones surgidas de actividades colaborativas-; y la coordinación necesaria para que el sistema como un todo actúe de manera coherente. Adicionalmente, debe existir una preocupación especial por que se desarrolle el mercado en aquellas áreas del sistema que produzcan "cuellos de botella" — como lo puede ser el mercado de capitales—, intentando generar "puentes" que terminen de conectar todos sus componentes.

\subsection{El sistema nacional de innovación chileno}

El Índice de Competitividad para el Crecimiento del World Economic Forum y el modelo desarrollado por el Banco Mundial para diagnosticar la posición de cada país en la economía del conocimiento (World Bank, 2004), y el informe de la OCDE (2003) coinciden en que el país presenta un Sistema Nacional de Innovación (SNI) subdesarrollado, insuficientemente preparado para hacer frente al desafío de crecer con equidad. Este rezago se hace evidente cuando se le compara con el conjunto de países en el próximo nivel de desarrollo, esto es, aquellos con un PIB por habitante PPC

${ }^{36}$ Evidencia al respecto se presenta en Hall (1992) y Hao y Jaffe (1993). 
mayor a US\$20.000 por año; y se hace dramático cuando se le compara con el subconjunto de países particularmente innovadores ${ }^{37}$.

El punto de partida para analizar estos rezagos es la definición misma del SNI chileno. Este sistema no está necesariamente diseñado ni constituido formalmente como tal, pero sí opera en la práctica. El SNI está integrado por las empresas, universidades, centros de investigación, agencias públicas y, en general, todas las organizaciones, privadas, públicas o mixtas, que contribuyen a acrecentar el nivel global de conocimiento en el país, mediante la creación, adaptación, o adopción de tecnologías. En este sistema se puede diferenciar entre los roles de diseño de políticas, financiamiento, y ejecución de las mismas, e identificar cómo los distintos actores desempeñan dichos roles, e interactúan unos con otros.

El Gráfico $\mathrm{N}^{\circ} 7$ describe esquemáticamente el SNI chileno. Se aprecia que en este sistema las políticas son diseñadas primordialmente por

\section{GRÁFICO N ${ }^{\circ}$ 7: SISTEMA NACIONAL DE INNOVACIÓN CHILENO}

\begin{tabular}{|c|c|c|c|c|c|}
\hline $\begin{array}{l}\text { SECTOR } \\
\text { PÚBLICO }\end{array}$ & & & & & \\
\hline \multirow{2}{*}{$\begin{array}{l}\text { DISEÑO DE } \\
\text { POLÍTICAS } \\
\text { PÚBLICAS, } \\
\text { AUTORIDAD } \\
\text { POLÍTICA }\end{array}$} & \multicolumn{5}{|l|}{ PRESIDENTE } \\
\hline & $\begin{array}{l}\text { MINIST. DE } \\
\text { EDUCACIÓN }\end{array}$ & $\begin{array}{l}\text { MINIST. DE } \\
\text { ECONOMİA }\end{array}$ & \multicolumn{2}{|c|}{ MIDEPLAN } & $\begin{array}{l}\text { OTROS } \\
\text { MINIST. } \\
\text { SECTORIA- } \\
\text { LES } \\
\text { (AGRICUL- } \\
\text { TURA, } \\
\text { SALUD, } \\
\text { DEFENSA) }\end{array}$ \\
\hline $\begin{array}{l}\text { FINANCIA- } \\
\text { MIENTO }\end{array}$ & $\begin{array}{l}\text { CONICYT } \\
\text { (FONDEF, } \\
\text { FONDECYT) }\end{array}$ & $\begin{array}{l}\text { CORFO } \\
\text { (FONTEC, } \\
\text { FDI) }\end{array}$ & \multicolumn{2}{|c|}{$\begin{array}{l}\text { MILENIUM } \\
\text { (BECAS) }\end{array}$} & $\begin{array}{l}\text { FONDOS } \\
\text { SECTORIA- } \\
\text { LES } \\
\text { (FIA, FIP, } \\
\text { OTROS) }\end{array}$ \\
\hline EJECUCIÓN & \multicolumn{3}{|c|}{$\begin{array}{l}\text { INCUBADORAS } \\
\text { UNIVERSITA- } \\
\text { RIAS } \\
\text { (ACCESS NOVA) }\end{array}$} & \multicolumn{2}{|c|}{$\begin{array}{l}\text { INSTITUTOS } \\
\text { TECNOLÓGICOS } \\
\text { (IFOP, INFOR, } \\
\text { INIA, CCHEN) }\end{array}$} \\
\hline $\begin{array}{l}\text { PROPIEDAD } \\
\text { MIXTA }\end{array}$ & \multicolumn{2}{|l|}{$\begin{array}{l}\text { CONSORCIOS } \\
\text { (BIOSIGMA) }\end{array}$} & \multicolumn{3}{|c|}{$\begin{array}{l}\text { INSTITUTOS } \\
\text { TECNOLÓGICOS } \\
\text { (FUNDACIÓN CHILE) }\end{array}$} \\
\hline $\begin{array}{l}\text { SECTOR } \\
\text { PRIVADO }\end{array}$ & EMPRESAS & $\begin{array}{l}\text { UNIVER- } \\
\text { SIDADES }\end{array}$ & $\begin{array}{l}\text { INSTIT } \\
\text { TECNO } \\
\text { COS } \\
\text { (CECS) }\end{array}$ & & $\begin{array}{l}\text { INCUBADO- } \\
\text { RAS } \\
\text { (OCTANTIS) }\end{array}$ \\
\hline
\end{tabular}

Fuente: Elaborado por los autores.

${ }^{37}$ Para efectos de las cifras comentadas en este documento, se considera como países especialmente innovadores a Corea del Sur, Finlandia, Israel, Singapur y Suecia. 
actores públicos. En este sentido, si bien algunos programas particulares cuentan con consejos asesores que consideran la opinión de actores privados, ello no se da al nivel agregado ni forma parte sistemática del diseño de las políticas de innovación como un todo. Esta visión global en teoría reside en la autoridad política del Presidente de la República; sin embargo, en la práctica ella sólo se traduce en prioridades anuales que quedan de manifiesto a través del proceso presupuestario del sector público. Es decir, no existe una instancia pública formal, ni menos mixta, que coordine, dé lineamientos generales, evalúe y vele por la consistencia del SNI. Como se identificó anteriormente, es esperable que esta coordinación no surja espontáneamente —es una de las fallas sistémicas del proceso innovador-, por lo que debe ser el sector público el que la fomente ${ }^{38}$.

Entre los actores públicos más relevantes en el diseño de políticas se cuenta el Ministerio de Educación y el Ministerio de Economía, el primero orientado a la investigación básica, y el segundo al desarrollo tecnológico y el emprendimiento innovador. Otro actor importante es Mideplan, a cargo del Programa Milenium de becas de investigación. Sin embargo, no hay instancias formales de coordinación entre estas líneas programáticas. Esta ausencia de coordinación se manifiesta también en la existencia de una serie de políticas diseñadas a nivel sectorial por los ministerios respectivos, por ejemplo en agricultura, salud, defensa y otros, así como por traslapes y duplicación de funciones.

En el nivel del financiamiento, destacan dos grandes fuentes. La primera, que primó hasta fines de la década de los 80 , consiste en destinar recursos públicos directamente a financiar la oferta, básicamente de universidades e institutos tecnológicos públicos —entre los que se siguen contando el INIA, el INFOR, el CIREN, el INN, el IFOP, la CCHEN, el Servicio Hidrográfico y Oceanográfico de la Armada, el Instituto Geográfico Militar y el INACH, entre otros. La segunda, privilegiada a partir de la década de los 90, consiste en la canalización de recursos a través de los Fondos Tecnológicos. Su creación, más allá de los problemas de coordinación identificados en el sistema como un todo y de eventuales problemas operativos, ha sido conceptualmente correcta por apuntar a una mayor participación de las empresas en el proceso innovador, incentivando así la demanda por innovación de manera que se conecte con la oferta y hacerla más pertinente en términos productivos. Otra característica de estos fondos es

${ }^{38}$ En los países innovadores existen distintas institucionalidades que se encargan de esta función. Por ejemplo, en Finlandia existe el Science and Technology Policy Council, el que asesora al Primer Ministro en la labor de dirigir el SNI; mientras que en Israel existe el Office of the Chief Scientist, con similar labor. 
su horizontalidad, en el sentido de procurar seguir a la demanda, sin diferenciar sectores industriales, etapas de desarrollo, ni tecnologías específicas a ser aplicadas.

Con todo, estos fondos distinguen cuatro ámbitos ${ }^{39}$. Primero, el financiamiento de investigación básica no necesariamente aplicada ni comercializable, abarcado por el FONDECYT — bajo CONICYT en el Ministerio de Educación. Segundo, el financiamiento de proyectos tecnológicos con potencial comercial pero con alta incertidumbre, abarcado por el FONTEC -bajo CORFO en el Ministerio de Economía. Tercero, el financiamiento de proyectos innovadores con elevadas externalidades, abarcado por el FDI en su línea de interés público — bajo CORFO. Y cuarto, el financiamiento de proyectos asociativos en torno a innovaciones tecnológicas, abarcado por la línea de apoyo pre-competitivo del FDI y por el FONDEF — bajo CONICYT-, este último incentivando asociaciones entre las instituciones investigadoras y las empresas.

Muchos de estos fondos individuales están bien evaluados ${ }^{40}$; sin embargo, como se mencionó, no están todo lo alineados que debieran en cuanto a sus mecanismos de financiamiento, asesoría, administración, ejecución y evaluación ${ }^{41}$. Esto se debe a la alta dispersión de programas, donde convive el tradicional financiamiento directo a la oferta con los nuevos fondos orientados a la demanda, y que queda manifiesta al poder distinguir al menos 30 programas o agencias públicas en el Sistema Nacional de Innovación ${ }^{42}$ (véase detalle en Cuadro $\mathrm{N}^{\circ} 1$, donde además se indica el presupuesto para el año 2004 de cada una de ellas como señal de dispersión de esfuerzos y posible limitante para lograr masa crítica y aprovechar economías de escala y de ámbito).

Finalmente, a nivel de ejecución, en el SNI chileno se debe destacar el rol de actores privados, como universidades y empresas en sus roles tradicionales y en roles incipientes, como incubadoras de negocios e institutos tecnológicos. También se cuentan los organismos público-privados, donde tradicionalmente se ha destacado la Fundación Chile como instituto tecnológico, y donde están surgiendo formas de colaboración aún en maduración, como los consorcios, donde se puede destacar BioSigma ${ }^{43}$.

\footnotetext{
${ }^{39}$ Para mayor detalle, véase Benavente (2004a).

40 Véase por ejemplo Universidad de Chile (2004a) y (2004b), Crespi y Muñoz (1998), y Gerens (1996a) y (1996b).

${ }^{41}$ Por ejemplo, Benavente (2004a) resalta que entre fondos como el FDI y el FONDEF existen traslapes respecto a los clientes que atienden y la falla de mercado que buscan corregir.

${ }^{42} \mathrm{Sin}$ considerar a las universidades estatales ni a las empresas públicas.

${ }_{43}$ Consorcio en el área de la biotecnología, formado por Codelco, el Gobierno de Chile y Nippon Mining \& Metals, con el fin de desarrollar aplicaciones patentables para la minería y la metalurgia.
} 
CUADRO N ${ }^{\circ}$ 1: $\quad$ PROGRAMAS PÚBLICOS DESTINADOS A CIENCIA Y TECNOLOGÍA, PRESUPUESTO 2004

\section{AGRICULTURA}

Fundación para la Innovación Agraria (FIA)

3.466

INIA

7.191

INFOR (Subsecretaría Agricultura)

CIREN (Subsecretaría Agricultura)

418

Fundación Chile

ECONOMÍA

FONTEC

Fondo de Desarrollo e Innovación (FDI CORFO)

Fondo innovación tecnológica Bío-Bío

Programa Desarrollo e Innovación Tecnológica

Programa de Desarrollo e Innovación Tecnológica $\quad 1.644$

$\begin{array}{lr}\text { Subsecretaría de Agricultura (FIA) } & 569\end{array}$

$\begin{array}{lr}\text { CONICYT } & 1.408\end{array}$

Fundación Chile $\quad 330$

INN 393

Programa de Marcas y Patentes $\quad 261$

Fondo de Investigación Pesquera (FIP) (Subsecretaría de Pesca) 2.211

IFOP (Subsecretaría de Pesca) $\quad 392$

Fundación Chile (CORFO)

$\begin{array}{ll}\text { Profo y Fat } & 13.484\end{array}$

\section{EDUCACIÓN}

$\begin{array}{lr}\text { FONDECYT (CONICYT) } & 21.263\end{array}$

$\begin{array}{lr}\text { FONDEF (CONICYT) } & 9.900\end{array}$

Becas Nacionales de Postgrado (CONICYT) 3.059

Programa de Ciencia para la Economía del Conocimiento (Banco Mundial) $\quad 5.129$

$\begin{array}{ll}\text { Programa Explora (CONICYT) } & 723\end{array}$

Instituto Astronómico Isaac Newton $\quad 55$

Fondo Desarrollo Institucional $\quad 8.313$

Fondo Desarrollo Institucional - Infraestructura $\quad 16.375$

\section{MIDEPLAN}

$\begin{array}{lr}\text { Programa Iniciativa Científica Millenium } & 3.610\end{array}$

$\begin{array}{lr}\text { Programa de Becas } & 5.180\end{array}$

MINERÍA

Comisión Chilena de Energía Nuclear $\quad 3.979$

$\begin{array}{ll}\text { SERNEAGEOMIN } & 4.060\end{array}$

\section{DEFENSA}

Servicio Hidrográfico y Oceanográfico de la Armada de Chile $\quad 2.563$

$\begin{array}{ll}\text { Instituto Geográfico Militar } & 1.102\end{array}$

Servicio Aerofotogramétrico de la FACH 407

RELACIONES EXTERIORES

$\begin{array}{lr}\text { Instituto Antártico Chileno } & 1.926\end{array}$

Total

138.438

$\begin{array}{lr}\text { Total (Mill. US\$) } & 222\end{array}$

Fuente: Elaborado por los autores sobre la base de información de la Dirección de Presupuestos. 
GRÁFICO No 8: $\quad$ GASTO EN INVESTIGACIÓN Y DESARROLLO, CHILE, 1975-2000

(Millones de US\$ de 1992)

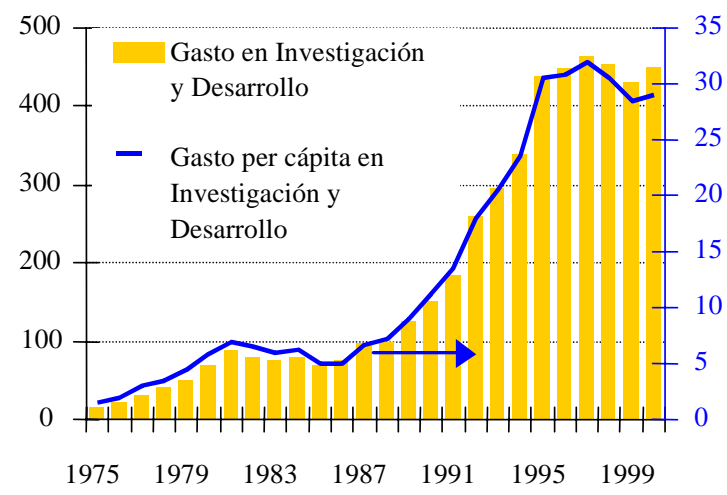

Fuente: Banco Mundial.

En el contexto descrito del SNI chileno, al problema de descoordinación y falta de directrices generales se suma una seria deficiencia en cuanto al monto del esfuerzo agregado en términos de recursos. Si bien este esfuerzo ha aumentado significativamente en los últimos años, al punto que el gasto en investigación y desarrollo en la década de los 90 más que cuadruplicó el de la década anterior (véase Gráfico $\mathrm{N}^{\circ}$ 8), éste sigue estando muy por debajo del de los países desarrollados y más aún de los innovadores $^{44}$. En efecto, mientras en Chile se destina en total el 0,7\% del PIB a estas actividades, en los países desarrollados se destina en promedio el 2,1\%, y en los innovadores el 3,1\%. Más aún, Lederman y Maloney (2003) muestran que Chile tiene un nivel de esfuerzo crecientemente menor al esperado si se controla por características económicas y poblacionales (véase Gráfico $\mathrm{N}^{\circ}$ 9).

Las comparaciones internacionales muestran que el esfuerzo chileno no es sólo bajo, incluso controlando por su nivel de ingresos y otras características, sino que además está mal distribuido, tanto en términos de quien lo financia, como en términos de su destino. En particular, se constata que en Chile la proporción del gasto en investigación y desarrollo financiada por las empresas privadas es menor al $28 \%$, mientras que el resto es financiado por el gobierno y las universidades. Esto contrasta con lo que ocurre

${ }^{44} \mathrm{Si}$ bien la investigación y desarrollo no es el único esfuerzo que los países realizan en términos de innovación, es la medida estándar utilizada en la literatura para realizar comparaciones. Con todo, esta medida debe ser tomada con precaución, por cuanto el esfuerzo del sector privado tiende a estar subdeclarado. 
GRÁFICO N 9: REZAGO EN GASTO EN INVESTIGACIÓN Y DESARROLLO, CHILE 1979$2000^{1}$

(\% del PIB)

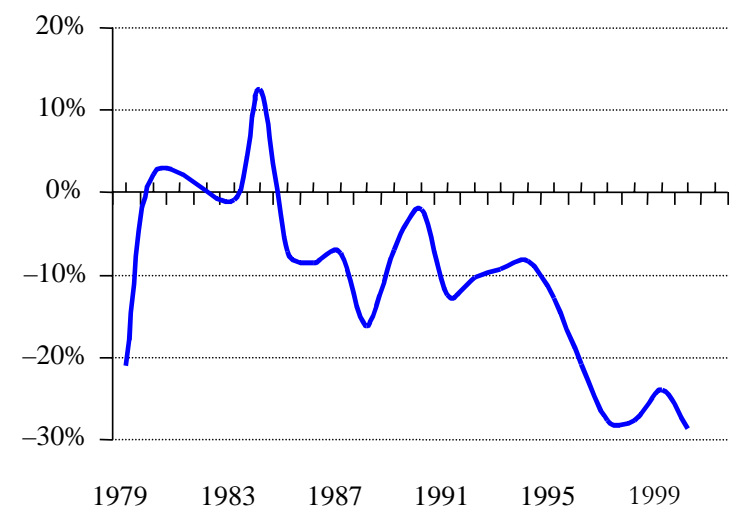

${ }^{1}$ El gráfico muestra la desviación entre gasto efectivo en investigación y desarrollo y el proyectado sobre la base del nivel de ingresos y el tamaño de la fuerza laboral del país. Cifras bajo el eje $\mathrm{X}$ corresponden a brechas negativas respecto a lo proyectado.

Fuente: Lederman y Maloney (2003).

en el conjunto de países innovadores, donde las empresas financian más de un $68 \%$. Esta última práctica es fundamental, ya que tiende a asegurar que la investigación sea pertinente a las necesidades del sector productivo y tenga efectos económicos reales. En Chile esto puede no estar ocurriendo en todo su potencial. Este temor se ve incrementado porque ni siquiera la investigación y desarrollo aplicada se realiza en forma mayoritaria en las empresas. En efecto, un muy bajo porcentaje de científicos en el área de la investigación y desarrollo trabaja en ellas - menos del 6\%, en contraste con Finlandia, en que lo hace más de un $30 \%$. En este mismo sentido, se verifica que un porcentaje desmedido del esfuerzo en investigación y desarrollo se dedica a investigación básica (en Chile menos de la mitad del esfuerzo total se focaliza en investigación aplicada, mientras que en los países innovadores esta proporción se eleva a más del $80 \%{ }^{45}$. Todo esto resulta en que la investigación en Chile no tienda a transformarse en aplicaciones comerciales (World Bank, 2004).

Lo anterior es señal de un bajo nivel de conexión entre el mundo empresarial y el científico-académico, lo que constituye una de las fallas

45 En el Cuadro $\mathrm{N}^{\circ} 1$ esta situación se refleja en la importancia relativa de los recursos ejecutados a través del Ministerio de Educación. Para mayor detalle de las comparaciones internacionales, véase Tokman y Zahler (2004). 
sistémicas clásicas que afectan el esfuerzo innovador. El rezago de Chile en superar esta falla se evidencia en el hecho que la colaboración con fines de investigación entre empresas y universidades en los países innovadores es casi un $60 \%$ más frecuente que en Chile. El deficiente nivel de interacción entre los agentes privados del SNI chileno también se manifiesta en que la principal fuente de innovación en las empresas son las personas al interior de las mismas, más que un proceso de aprendizaje por interacción con agentes externos, o al menos por observación de los mismos (Benavente, 2004).

Con todo, un elemento destacable de la acción de los agentes privados en el SNI ha sido la incipiente formación, gracias en parte a apoyos públicos, de clusters en torno a los recursos naturales. En este sentido, el ejemplo más notable es el cluster del salmón, por el nivel de desarrollo alcanzado (analizado en detalle en Montero, 2004, y Ulloa, 2004). Otros clusters dignos de mencionar, aunque con niveles de desarrollo menos maduros, son el minero (analizado en Ramos, 1999, y Ulloa, 2004) y el agro-frutícola (analizado en World Bank, 2004). En el contexto de estos clusters las empresas aprovechan tanto economías pecuniarias - comparten costos, por ejemplo en infraestructura-, como no pecuniarias - aprovechan dinámicas de aprendizaje y de transferencia tecnológica. Se crea además un campo fértil para acciones conjuntas de cooperación, por reducirse los costos de transacción y monitoreo. Todo esto atenúa parte de las fallas de mercado y sistémicas que llevan a que se innove menos que el óptimo social. Así, un buen ejemplo del mayor nivel innovador en los clusters son los encadenamientos hacia atrás para el desarrollo de insumos a la medida y de capital humano específico, sustentados en relaciones de largo plazo con los proveedores.

Este incipiente desarrollo de complejos productivos y su impacto en el esfuerzo innovador en el SNI chileno, si bien es alentador, parece todavía insuficiente. Aún en clusters en vías de madurez persisten fallas de mercado y sistémicas que limitan su esfuerzo innovador; mientras que otros clusters no se desarrollan, precisamente, por la magnitud de estas fallas. Así, puede ser deseable acelerar y fortalecer la creación de estos clusters mediante la acción de políticas públicas. Autores como Ramos (1999) afirman que es deseable acelerar su madurez para lograr incluso en la mitad del tiempo lo alcanzado por los países ricos en recursos naturales actualmente desarrollados. Más aún, De Ferranti et al. (2003) sugieren que las políticas de capacitación y de promoción de la investigación y desarrollo pueden ser eficientemente implementadas al nivel de clusters específicos, y ser moldeadas a sus necesidades particulares. 
El bajo esfuerzo innovador del sector privado también se debe a las fallas del mercado de capitales que dificultan el financiamiento del emprendimiento innovador. Es así como en los países innovadores los empresarios perciben que existe una disponibilidad de capital de riesgo al menos 50\% superior a la existente en Chile. Con todo, debe destacarse que paulatinamente estas fallas de mercado se han ido corrigiendo a través de los proyectos de Ley de Mercado de Capitales I y II, partiendo por los niveles más básicos de funcionamiento del mercado y avanzando hacia niveles de mayor sofisticación. Paralelamente, la disponibilidad de fondos públicos orientados al financiamiento del proceso innovador también ha apuntado a suplir la ausencia de mercado. De esta manera, a la fecha los fondos públicos han apuntado a financiar las etapas de "desarrollo del concepto" y "desarrollo o transferencia de tecnología", mientras que los proyectos de Ley de Mercado de Capitales han apuntado a desarrollar el financiamiento privado de las etapas de "desarrollo inicial de la empresa" y "expansión". Así se estarían cubriendo todas las fases del financiamiento de la innovación. Por una parte, fondos públicos apoyan la generación de ideas y, por otra, se desarrolla el mercado para que fondos privados las transformen en negocios. La excepción en la cobertura de este esquema es la etapa de "aplicación y primer escalamiento", la que estaría quedando rezagada y debiese cubrirse mediante el desarrollo del capital semilla (véase Gráfico $\mathrm{N}^{\circ} 10$ ).

Dado los problemas identificados en el SNI chileno, a saber, falta de directrices, descoordinación, duplicidad de funciones, bajo esfuerzo total, dispersión de programas que no alcanzan a crear masa crítica, baja participación del sector privado, sesgo hacia la investigación básica, falta de financiamiento, "cuellos de botella" en materia de capital humano, y desconexión entre el ámbito empresarial y el ámbito investigador-académico, no es de extrañar que el sistema presente además un bajo nivel de eficiencia. Esto, a pesar que se han identificado mejoras en la última década, como la incipiente creación de clusters, el aumento del esfuerzo público en investigación y desarrollo - especialmente a través de la creación de fondos tecnológicos-, y las mejoras en marcha en el mercado de capitales. En efecto, mediciones recientes determinan que la eficiencia del esfuerzo innovador en Chile está por debajo del rendimiento promedio de los países de la OCDE, aún controlando por nivel de esfuerzo ${ }^{46}$. Esta brecha se hace

${ }^{46}$ Esta medición de eficiencia se refiere a la capacidad para transformar la inversión en investigación y desarrollo en innovaciones patentables a nivel comercial. Para mayores detalles, véase Lederman y Maloney (2004) y Bosch, Lederman y Maloney (2004). El patentamiento de innovaciones es la medida más utilizada en la literatura para evaluar el rendimiento del esfuerzo innovador. Una medida alternativa podría ser la diversificación de productos de 
GRÁFICO N 10: FINANCIAMIENTO DE LA INNOVACIÓN Y FASES DE DESARROLLO

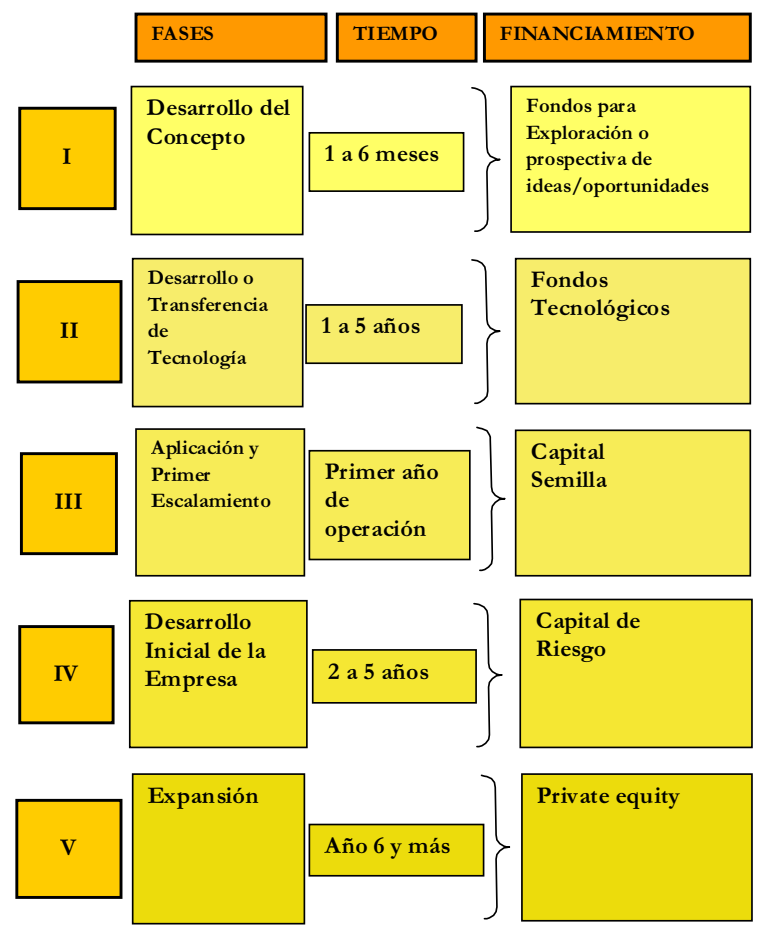

Fuente: Fundación Chile.

más notoria al compararse con el conjunto de países innovadores. En resumen, se concluye que Chile presenta hoy un SNI en el que el esfuerzo innovador es bajo —especialmente el del sector privado— y además poco eficiente.

\section{Capital humano, crecimiento y equidad}

Para poder establecer claramente la relación entre políticas educativas, crecimiento y equidad, es necesario dar cuenta de dos eslabones fundamentales. Primero, que el capital humano forma parte de los factores

exportación. Si bien no hay comparaciones internacionales estandarizadas al respecto, para el caso chileno se destaca que mientras en 1975 se exportaban 200 productos, hoy se exportan cerca de 4 mil, aunque este aumento no ha ido emparejado con un incremento equivalente en el número de patentes comercializables. 
claves que permiten generar innovación e ingresos, ya sea al nivel individual, regional o nacional. Y segundo, que existen importantes fallas de mercado asociadas a la inversión en educación que justifican la intervención estatal.

La importancia del capital humano en la generación de innovación e ingresos está presente en todas las teorías recientes de crecimiento y desarrollo económico. Dicho aporte se manifiesta primordialmente a través del aumento en la productividad, al facilitar la adopción de tecnologías y procesos productivos más sofisticados y flexibles. La contribución del capital humano al crecimiento se encuentra respaldada por una extensa investigación empírica (véase World Bank, 1995) que muestra que buena parte del crecimiento económico de los países es explicado por la Productividad Total de Factores (PTF) y que un elemento clave para el crecimiento de ésta corresponde a la calidad de la educación. A este respecto se ha argumentado que si Chile mejorase de una vez y para siempre la calidad de la educación, la productividad aumentaría a medida que las nuevas generaciones se incorporasen a la fuerza de trabajo (Beyer y Vergara, 2002). Empíricamente se ha estimado que un aumento en la calidad de la educación consecuente con el logro de resultados promedio para el nivel de ingreso del país llevaría a aumentos de hasta 0,7 puntos porcentuales en la $\mathrm{PTF}^{47}$.

Una forma alternativa mediante la cual es posible dimensionar el impacto del capital humano sobre la capacidad de generación de ingresos es a través de las estimaciones de rentabilidad social y privada de la educación. El Cuadro $\mathrm{N}^{\circ} 2$ muestra estimaciones en las que es posible observar: (i) que la educación es una inversión altamente rentable, tanto para los

CUADRO N ${ }^{\circ}$ 2: $\quad$ RETORNOS A LA INVERSIÓN EN EDUCACIÓN POR NIVEL E INGRESO POR HABITANTE $(\%)$

\begin{tabular}{|c|c|c|c|c|c|c|}
\hline \multirow{2}{*}{$\begin{array}{l}\text { Grupo de ingreso } \\
\text { por habitante }\end{array}$} & \multicolumn{3}{|c|}{ Social } & \multicolumn{3}{|c|}{ Privado } \\
\hline & Básica & Media & Superior & Básica & Media & Superior \\
\hline Ingresos bajos (US\$ 755 o menos) & 21,3 & 15,7 & 11,2 & 25,8 & 19,9 & 26,0 \\
\hline Ingresos medios (hasta US\$ 9.265) & 18,8 & 12,9 & 11,3 & 27,4 & 18,0 & 19,3 \\
\hline Ingresos altos (US\$ 9.266 o más) & 13,4 & 10,3 & 9,5 & 25,6 & 12,2 & 12,4 \\
\hline Mundo & 18,9 & 13,1 & 10,8 & 26,6 & 17,0 & 19,0 \\
\hline
\end{tabular}

Fuente: Psacharopoulos y Patrinos (2002).

${ }^{47}$ Para mayores detalles, véase Barro (1999) y Gallego y Loayza (2002). 
gobiernos como para los individuos; (ii) que la rentabilidad privada de la educación es por lo general mayor que la social, debido a que los gobiernos asumen gran parte de los costos en la práctica; (iii) que mientras la mayor rentabilidad social se encuentra en la educación primaria, las tasas de rentabilidad privada son también altas para la educación superior en los países de ingresos medios y altos; y (iv) que la rentabilidad privada y social de la educación tiende a reducirse en los países de mayor desarrollo.

La realidad de prácticamente todos los países del mundo es que la mayor parte de la inversión en educación es realizada por el Estado, generalmente financiando sistemas públicos de enseñanza. La intervención del Estado, que además del financiamiento abarca regulación y producción, se explica principalmente por la presencia de severas fallas de mercado. Entre éstas se pueden citar: (i) el plazo extremadamente largo de maduración que requiere la inversión en educación —especialmente en el nivel primariolo que maximiza la distorsión que generan los diferenciales de tasas privadas y sociales de descuento intertemporal; (ii) los altos riesgos asociados a la inversión, dada la alta dispersión de ingresos que se produce entre trabajadores de niveles similares de educación; (iii) la imposibilidad de aportar capital humano como colateral para la obtención de financiamiento; y (iv) las externalidades que genera el aumento de los niveles educativos de la población y la formación en determinadas áreas y especialidades.

\subsection{Capital humano y calidad de la educación escolar}

El fuerte esfuerzo en términos de inversión pública en educación en las últimas décadas ha resultado en un significativo y progresivo aumento de cobertura, el que a la vez ha permitido que se incremente sostenidamente la escolaridad de la población en Chile $^{48}$. No obstante estos logros en términos de cobertura, la discusión pública ha estado marcada en los últimos años por una alta y creciente preocupación por la calidad de la educación. La preocupación ha surgido tanto del análisis de la evolución de los resultados de la prueba SIMCE, como de los resultados de instrumentos estandarizados internacionalmente, específicamente: el Estudio Internacional de Tendencias en Matemáticas y Ciencias (TIMSS), aplicado a alumnos de $8^{\circ}$ grado en 2002; y el Programa para la Evaluación Internacional de Estudiantes (PISA), aplicado a estudiantes de 15 años en el año 2000. En estas dos pruebas los estudiantes chilenos se ubicaron entre los más bajos de las muestras respectivas: en el TIMSS, entre 46 países Chile ocupó el

${ }^{48} \mathrm{La}$ escolaridad promedio de la población mayor de 15 años pasó de 7,4 años en 1975 a 8,6 en 1990, y se estima que llegará a 10,8 en 2005. 
GRÁFICO N ${ }^{\circ}$ 11: PROMEDIO PUNTAJE PISA Y GASTO ANUAL POR ALUMNO EN PRIMARIA Y SECUNDARIA EN RELACIÓN AL PIB POR HABITANTE

(Puntaje; gasto/PIB por habitante)

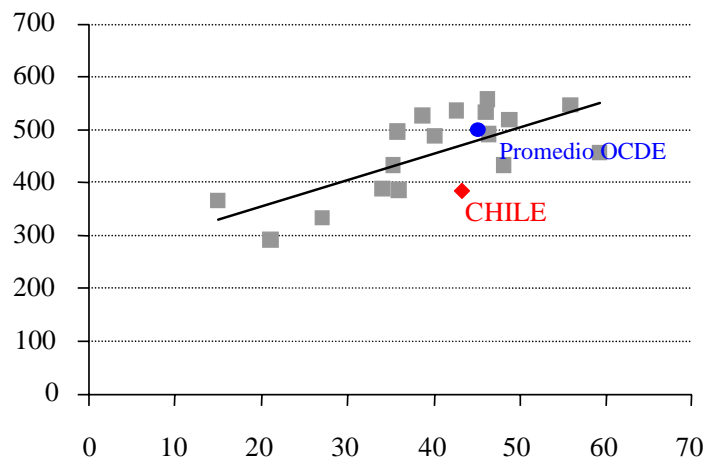

Fuente: Elaborado por los autores sobre la base de estadísticas OCDE y PISA.

lugar 39 en matemáticas y el lugar 36 en ciencias; y en la prueba PISA el lugar 34 entre 41. Ciertamente, Chile es superado por aquellos países con un mayor nivel de desarrollo, especialmente por los más innovadores ${ }^{49}$. Sin embargo, los estudiantes chilenos muestran rendimientos incluso inferiores a los esperados para el nivel de gasto en educación por estudiante del país, controlando por su nivel de desarrollo (véase Gráfico $\mathrm{N}^{\circ} 11$ para el caso de la prueba PISA).

Otra señal de alerta respecto a la calidad de la educación escolar en Chile surge de las evaluaciones internacionales de competencias laborales. El estudio sobre alfabetización adulta (IALS) de la OCDE concluyó que en 1998 sólo el 12,9\% de los trabajadores chilenos de entre 16 y 65 años mostraba competencias superiores al nivel básico, mientras que en países innovadores como Finlandia este porcentaje llegaba a 63,6\% ${ }^{50}$.

Todas estas comparaciones internacionales hacen evidente que Chile debe aún recorrer un trecho importante en el mejoramiento de la calidad de su educación. Para ello no basta una mayor inversión pública en educación, pues los mismos estudios internacionales muestran que Chile presenta rendimientos inferiores a los que indicaría su actual nivel de gasto por estudiante. Por lo tanto, para mejorar la calidad es preciso identificar clara-

${ }^{49}$ Por ejemplo, en el TIMSS Singapur presenta un rendimiento 56\% superior a Chile en matemáticas y $40 \%$ superior en ciencias. Mientras que Corea del Sur nos supera por un $52 \%$ y un $35 \%$ en matemáticas y ciencias, respectivamente.

${ }^{50}$ Estos preocupantes resultados son especialmente indicativos de la mala calidad de la educación chilena en la década del 80 — debido a que la mayor parte de la fuerza de trabajo en 1998 había pasado por el sistema educacional en ese período. 
mente sus determinantes y focalizar los esfuerzos en ellos. Al respecto, una conclusión esencial de la literatura especializada es el reconocimiento de la complejidad del proceso enseñanza-aprendizaje en un sistema en el cual participan numerosos actores que interactúan en distintos niveles y procesos, afectando positiva o negativamente el logro de resultados. A saber, importan: a) Los estudiantes, sus familias y su preparación para la escuela; b) Los profesores y alumnos en la sala de clase; c) La gestión escolar a nivel de establecimiento; y d) El sistema educacional.

\section{a) Los estudiantes, sus familias y su preparación para la escuela}

Diversos estudios han constatado una relación robusta y positiva entre el rendimiento escolar y la condición socioeconómica de los hogares de los niños que participan en el sistema educacional chileno ${ }^{51}$. Concretamente, el nivel socioeconómico de las familias influye sobre el rendimiento escolar a través de los recursos que el hogar proporciona para apoyar el proceso educativo, entre los que se destaca: la educación de la madre, la disponibilidad de útiles y textos, las condiciones materiales que el hogar proporciona para estudiar, y las presiones para que niños y jóvenes trabajen para complementar el ingreso familiar. No sorprende que los hogares más pobres estén desaventajados en estos factores ${ }^{52}$, y generen por tanto menores posibilidades de desarrollo psicomotor, de aptitudes y de conductas para los niños, afectando así su capacidad de aprender en el sistema educacional formal.

Una respuesta parcial a las desventajas que enfrentan los menores de hogares pobres puede darla el sistema de educación prebásico. A este respecto, si bien en Chile el acceso al sistema preescolar para los niños de hogares más pobres ha mejorado significativamente desde 1990 (Gráfico $\mathrm{N}^{\circ} 12$ ), aún los niveles absolutos de cobertura parecen insuficientes para compensar las desventajas que enfrentan estos niños.

\section{b) Los profesores y alumnos en la sala de clases}

El grueso de las actividades propias del proceso educativo ocurre en la sala de clases, en la interacción regular e intensiva entre el docente y sus

${ }^{51}$ Por ejemplo, Mizala, Romaguera y Farren (1998) demuestran, en base a resultados de la prueba SIMCE por establecimiento, que las variables socioeconómicas se encuentran entre las más importantes para explicar el logro de los alumnos.

${ }^{52}$ Por ejemplo, la Encuesta CASEN 2003 muestra que la educación de la madre crece con el ingreso del hogar (mientras en el primer quintil llega a 8,6 años, en el quinto llega a 14,3); mientras que el nivel de hacinamiento disminuye (mientras en el primer quintil en promedio hay 3,4 personas por dormitorio, en el quinto hay sólo 2,0 ). 
GRÁFICO N¹2: $\quad$ COBERTURA EDUCACIÓN PREESCOLAR POR QUINTIL DE INGRESOS, 1990 Y $2003(\%)$

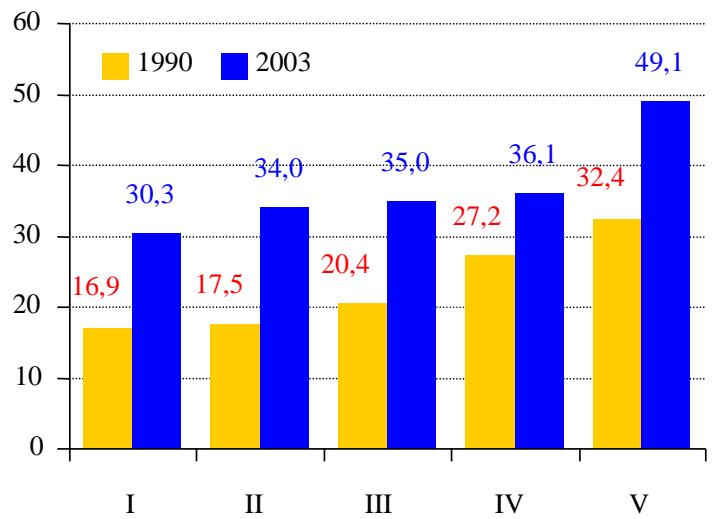

Fuente: Mideplan.

alumnos, y entre estos últimos. Para que este proceso rinda buenos resultados se requiere de tiempo suficiente, contenidos sustantivos, recursos apropiados, metodologías eficaces y profesores preparados y motivados para aplicarlas. En este sentido, la Reforma Educacional iniciada en la década del 90 ha focalizado sus esfuerzos en el fortalecimiento del proceso de enseñanza-aprendizaje en varias de las dimensiones anotadas. La efectividad de estos cambios, sin embargo, depende en última instancia de la motivación, confianza y calificación que aporten los docentes. La literatura coincide en identificar tres variables claves que definen a un docente efectivo $^{53}$ : (i) conocimiento de los contenidos de la enseñanza; (ii) manejo de un repertorio amplio de técnicas pedagógicas; y (iii) motivación. De estas variables, la última es la más compleja de intervenir a través de políticas públicas, aunque normalmente se arguye para mejoramientos salariales y la estructuración de carreras docentes ${ }^{54}$. En el caso de Chile estos mejoramientos han sido muy significativos a partir de los $90^{55}$. De hecho, actualmente las remuneraciones docentes son superiores al ingreso por habitante del país, situándolos en una posición favorable, especialmente al inicio de sus carreras. Esta posición se atenúa, sin embargo, a medida que los docentes acumulan experiencia y avanzan en su escala salarial. Esto evidencia

53 Para mayores detalles, véase Lockheed y Verspoor (1991).

${ }^{54}$ En general, existe consenso entre expertos y planificadores educacionales en cuanto a la baja relación costo-efectividad de los mejoramientos salariales docentes. Al respecto, véase Schieffelbein, Wolff y Schieffelbein (1998).

55 Véase Mizala y Romaguera (2000). 
CUADRO N ${ }^{\circ}$ : $\quad$ SALARIO DOCENTE EN RELACIÓN A PIB POR HABITANTE

\begin{tabular}{|c|c|c|c|}
\hline & \multicolumn{3}{|c|}{ Primaria } \\
\hline & Inicial & $\begin{array}{l}\text { Con } 15 \text { años } \\
\text { experiencia }\end{array}$ & $\begin{array}{c}\text { Máximo de } \\
\text { la escala }\end{array}$ \\
\hline Chile & 1,1 & 1,3 & 1,4 \\
\hline \multicolumn{4}{|l|}{ Países con PIB por habitante } \\
\hline $\mathrm{PPC}>\mathrm{US} \$ 20.000$ & 0,9 & 1,3 & 1,5 \\
\hline \multirow{3}{*}{ Países innovadores } & 1,1 & 1,6 & 2,3 \\
\hline & \multicolumn{3}{|c|}{ Secundaria inferior } \\
\hline & Inicial & $\begin{array}{l}\text { Con } 15 \text { años } \\
\text { experiencia }\end{array}$ & $\begin{array}{c}\text { Máximo de } \\
\text { la escala }\end{array}$ \\
\hline Chile & 1,1 & 1,3 & 1,4 \\
\hline \multicolumn{4}{|l|}{ Países con PIB por habitante } \\
\hline $\mathrm{PPC}>\mathrm{US} \$ 20.000$ & 1,0 & 1,3 & 1,5 \\
\hline Países innovadores & 1,2 & 1,7 & 2,3 \\
\hline
\end{tabular}

Fuente: Elaborado por los autores sobre la base de información OCDE.

una estructura salarial excesivamente comprimida (Cuadro $\mathrm{N}^{\circ} 3$ ), con pocos incentivos a la acumulación de experiencia, calificación y desempeño, lo que torna particularmente relevante para Chile la introducción de esquemas de remuneración ligada al desempeño.

\section{c) La gestión escolar a nivel de establecimiento}

La evidencia muestra que las escuelas que obtienen un rendimiento sustancialmente superior a lo esperado para sus variables de contexto cuentan con un alto sentido de misión, mayor autonomía, liderazgo directivo, un clima organizacional positivo, una gestión responsable y una alta preocupación por los resultados. Se argumenta que para lograr estas características, la escuela necesariamente requiere autonomía de gestión.

En Chile, la descentralización educativa parece expresarse en aspectos tales como la municipalización de las escuelas públicas, el régimen de subvenciones, la libre elección de establecimientos, el estímulo a la formación de programas de mejoramiento educativo y la flexibilidad para diseñar programas de estudio por establecimiento. El grado de descentralización en el sistema educativo, sin embargo, depende de la real autonomía con que cuenten las escuelas para adoptar decisiones en los planos técnico-pedagó- 
gico y administrativo. El Estatuto Docente ha sido recurrentemente criticado, precisamente, por limitar la autonomía de las escuelas municipales en la adopción de decisiones respecto a los profesores (por ejemplo, en lo referido a su despido y a la determinación de sus remuneraciones). Con todo, las rigideces a la gestión de los establecimientos se extienden mucho más allá de lo establecido en el Estatuto Docente. Es así como sólo 851 de poco más de 3.000 directores cuentan con facultades de administración delegadas por parte del alcalde. Pese a que el Estatuto Docente no impide que el establecimiento participe en la selección de nuevo personal, una encuesta reciente entre directivos de escuelas y liceos municipalizados señaló que un $70 \%$ de los directivos de básica y un 30\% de los directivos de media no tenía participación en estas decisiones. Del mismo modo, una alta proporción de directores de establecimientos municipales no maneja recurso financiero alguno, debiendo recurrir a la municipalidad para la provisión de los bienes y servicios más elementales para el funcionamiento de la escuela. Esta situación se ve agravada por dos factores: las características y capacidades de los directores, y el grado de integración de la comunidad escolar. La situación de los directores de establecimientos municipales es a este respecto particularmente grave, pues aún se mantienen casi 2.000 directores con carácter de inamovible. Por su parte, la participación de los padres en actividades de la escuela parece estar concentrada exclusivamente en la asistencia a reuniones de apoderados ${ }^{56}$. Por tanto, no parecen registrarse en el sistema grandes presiones por adoptar un estilo de gestión que involucre más activamente a la comunidad.

De este modo, un sistema educacional aparentemente descentralizado en lo orgánico, no lo es tanto desde la perspectiva de la propia escuela, lo que pone en duda que ésta sea efectivamente la unidad básica del sistema. Aunque resulta innegable que el Estatuto Docente introdujo un elemento importante de rigidez administrativa en el sector municipal, no es menos cierto que existe un amplio espacio para el ejercicio de mayor autonomía en las escuelas de este sector que está siendo subutilizado. Con todo, la hipótesis de la flexibilidad administrativa como base de la calidad educacional es puesta en duda por el rendimiento obtenido por los alumnos de los establecimientos con los máximos niveles de autonomía en su gestión. En efecto, el estudio PISA muestra que el rendimiento del 10\% mejor de los estudiantes chilenos — que en su mayoría asiste a colegios de elite altamente autónomos- apenas alcanza al puntaje más bajo del 10\% superior de los países más avanzados.

${ }^{56}$ Antecedentes citados en Brunner y Elacqua (2003). 


\section{d) El sistema educacional}

Un sistema educacional que opere como tal requiere de al menos tres elementos: (i) un sistema de asignación de recursos; (ii) mecanismos de coordinación; y (iii) una instancia de formulación de políticas, programación y evaluación. Estos elementos son esenciales para resolver el dilema de cómo hacer que la educación responda a los requerimientos de la sociedad y sea capaz de aprender de la multiplicidad de experiencias que se dan en su interior.

A este respecto, la reforma de 1980 buscó desarrollar un mecanismo de cuasi-mercado educativo para resolver los requerimientos de coordinación y trasladó las responsabilidades por la programación y evaluación a los sostenedores educacionales y a las familias. Así, Chile estableció uno de los sistemas orgánicamente más descentralizados del mundo, en el que el Ministerio de Educación no cuenta con facultades para intervenir directamente sobre la gestión de ninguno de los 4.142 sostenedores ni sobre el funcionamiento de sus 10.642 escuelas. En un sistema con este grado de dispersión los requerimientos de coordinación y evaluación se vuelven especialmente apremiantes. En el cuasi-mercado educativo chileno estas necesidades se resuelven entregando a las familias no sólo la capacidad de escoger la escuela para sus hijos, sino también la capacidad para aplicar los recursos públicos que pagan por el servicio. En la racionalidad de este sistema, si son las mejores escuelas las que atraen a un mayor número de niños y si éstos traen consigo los recursos financieros correspondientes, la competencia por captar y retener alumnos debiese encargarse no sólo de asignar los recursos con eficiencia, sino de elevar el rendimiento global del sistema.

Una consecuencia inmediata de la reforma de 1980 fue el rápido desarrollo y consolidación de la educación particular subvencionada, que en la actualidad abarca a cerca del $40 \%$ de los alumnos del sistema. Esto se ha interpretado como señal inequívoca del éxito de la reforma, sin embargo, la realidad es más matizada. Por una parte, parece bastante claro que el régimen de subvenciones ha contribuido a elevar la eficiencia en la asignación de recursos y a ampliar la cobertura del sistema educacional. Del mismo modo, todo indica que las familias valoran la libertad de elección que este sistema les ofrece. No obstante, no existe evidencia que permita concluir que el régimen de subvenciones haya permitido mejorar la calidad de la educación en Chile, apreciándose en cambio rasgos de selección de estudiantes y segmentación del sistema que atentan contra la pluralidad y equidad que se espera del mismo. En efecto, se verifica que los estableci- 
CUADRO N ${ }^{\circ}$ 4: $\quad$ PUNTAJE SIMCE POR GRUPO SOCIOECONÓMICO Y DEPENDENCIA, 20012003. SEGUNDO MEDIO, PUNTAJE PROMEDIO

\begin{tabular}{|c|c|c|c|}
\hline & \multicolumn{3}{|c|}{ Matemáticas } \\
\hline & Municipal & $\begin{array}{c}\text { Particular } \\
\text { subvencionado }\end{array}$ & $\begin{array}{c}\text { Particular } \\
\text { pagado }\end{array}$ \\
\hline Bajo & 215 & 220 & - \\
\hline Medio bajo & 223 & 235 & - \\
\hline Medio & 270 & 265 & - \\
\hline Medio Alto & $347^{1}$ & 294 & 301 \\
\hline Alto & - & - & 325 \\
\hline \multirow[t]{3}{*}{ Totales nacionales } & 241 & 257 & 301 \\
\hline & \multicolumn{3}{|c|}{ Lenguaje } \\
\hline & Municipal & $\begin{array}{c}\text { Particular } \\
\text { subvencionado }\end{array}$ & $\begin{array}{c}\text { Particular } \\
\text { pagado }\end{array}$ \\
\hline Bajo & 226 & 229 & - \\
\hline Medio bajo & 238 & 245 & - \\
\hline Medio & 273 & 270 & - \\
\hline Medio Alto & $317^{1}$ & 289 & 292 \\
\hline Alto & - & - & 306 \\
\hline Totales nacionales & 230 & 250 & 317 \\
\hline
\end{tabular}

${ }^{1}$ Los establecimientos municipales del grupo socioeconómico Medio Alto agruparon a $1 \%$ del total de alumnos en 2003. Para el año 2001, en cambio, no se informó de puntajes para esta categoría de establecimientos, porque agrupaban un número muy bajo de alumnos. Por esta razón, las variaciones de los establecimientos Municipales-Medio Alto se calcularon considerando las variaciones de aquellos establecimientos clasificados en esta categoría para la prueba 2003.

Fuente: SIMCE.

mientos particulares subvencionados tienden a mostrar rendimientos superiores a los del sector municipal, pero fundamentalmente por el perfil socioeconómico de sus alumnos. De hecho, cuando las comparaciones de los puntajes SIMCE se hacen para alumnos de similar condición socioeconómica, las diferencias se vuelven virtualmente irrelevantes (Cuadro $\left.\mathrm{N}^{\circ} 4\right)^{57}$.

En buena medida la estructura que se ha generado se deriva de la manera en que las familias han escogido las escuelas de sus hijos. Los resultados de encuestas aplicadas a padres y apoderados indican que mien-

${ }^{57}$ Para mayor detalle sobre la evidencia econométrica al respecto, véase Tokman (2002). 
tras las familias de menores recursos tienden a adoptar criterios esencialmente prácticos, como la cercanía del establecimiento, su costo y la formación en una profesión u oficio, las familias de estratos medios y altos adoptan criterios esencialmente asociados al estatus, como el prestigio del establecimiento y los valores que entrega. En ninguno de estos grupos el puntaje SIMCE incide de manera importante en las decisiones de los padres y sólo los sectores medios y altos asignan alguna ponderación a los resultados de las pruebas de acceso a la educación superior. Estos criterios de decisión están relacionados con un problema fundamental de la educación como inversión, cual es el de las asimetrías de información. Los plazos excesivamente largos entre el proceso educativo y su impacto sobre la inserción laboral o profesional, el desconocimiento de los padres sobre "la función de producción" educacional, y la abundancia de elementos cualitativos, constituyen fallas de información muy profundas que afectan la capacidad de decisión de las familias. Estas fallas son más profundas mientras menos estandarizada y definida es la información sobre desempeño de las escuelas y mientras mayor flexibilidad tienen éstas para formular su proyecto educativo. En particular, la mejor imagen que proyectan los establecimientos particulares subvencionados hace que opere la lógica de un mercado en el que las decisiones de los oferentes se imponen sobre las de los demandantes ("sellers' market"). Estos procesos son los que han ido profundizando la homogeneización social en las escuelas, concentrándose una proporción creciente de la población de mayores ingresos en el sector particular $^{58}$.

La dinámica del cuasi-mercado educativo en Chile no sólo ha sido incapaz de elevar el rendimiento global del sistema, sino que además ha sido incapaz de garantizar una educación de excelencia para la elite. A este respecto, como se señaló anteriormente, el estudio PISA muestra que el rendimiento del $10 \%$ mejor de los estudiantes chilenos apenas alcanza al puntaje más bajo del $10 \%$ superior de los países más avanzados. Estos resultados no sólo ponen en duda la suficiencia de la flexibilidad administrativa como garantía de un buen rendimiento escolar, sino que también la relevancia del gasto por estudiante, pues los establecimientos de elite que producen los resultados señalados corresponden precisamente a aquellos que cuentan con los máximos niveles de autonomía en su gestión y que cobran elevados aranceles a los padres. Paralelamente, la evidencia recogida de la prueba SIMCE permite distinguir a un importante conjunto de

${ }^{58}$ Este fenómeno se aprecia también en el análisis de los resultados del estudio PISA, donde se detecta que prácticamente toda la varianza en condiciones socioeconómicas de los alumnos en Chile se produce entre establecimientos, con variaciones mínimas al interior de cada uno de ellos (Mineduc, 2004). 
escuelas con altos niveles de efectividad pese a atender a niños y niñas de escasos recursos.

Todo lo anterior indica que el cuasi-mercado es un mecanismo insuficiente y potencialmente discriminatorio de coordinación, pero aún así no ha llegado a generar un determinismo social en el proceso educativo. Más bien ha tendido a estructurar un sistema educativo autorreferente que enfrenta pocos incentivos para elevar su rendimiento. El costo de cambiar este sistema mediante programas y subsidios estatales es altísimo y, probablemente, con rendimientos decrecientes mientras las reglas del juego sean relativamente débiles, las evaluaciones sean sin estándares, las subvenciones se entreguen con pocas exigencias, y exista un deficiente sistema de supervisión.

\subsection{Educación superior}

Para enfrentar el desafío de la economía del conocimiento importa también la calidad, cobertura y equidad en acceso a la educación superior. En este sentido, actualmente Chile presenta una cobertura significativamente inferior a la de los países innovadores (37,5\% versus 63,6\%). Sin embargo, se espera que nuestro país experimente una creciente demanda por educación superior en los próximos años. En efecto, el aumento de cobertura en la educación media, la disminución de las tasas de repetición en todo el sistema, y el remanente de la curva demográfica ascendente para los jóvenes de este tramo de edad determinan que el flujo de egresados de la educación media experimentará un fuerte incremento entre 2004 y 2008 (véase Gráfico $\mathrm{N}^{\circ} 13$ ). Esto se refuerza con las altas y crecientes expectativas de estos jóvenes y sus familias por ingresar a la universidad.

La materialización de esta demanda ayudará a reducir la brecha de técnicos y profesionales en la fuerza laboral chilena respecto a la de los países innovadores (estadísticas del Banco Mundial indican que en Chile sólo un 10,2\% de la fuerza laboral es técnico-profesional, en contraste con los países innovadores, donde esta cifra se eleva al 29,2\%). Eventualmente también ayudará a disminuir la brecha de profesionales con doctorado en la fuerza laboral (Tokman y Zahler, 2004, muestran que en el período 19961999 Chile incorporó a su fuerza laboral sólo $3 \mathrm{PhD}$ en ciencia por cada millón de habitantes, mientras que Suecia y Finlandia incorporaron 197 y 177, respectivamente).

Sin embargo, la eficiencia global de la inversión pública y privada en educación superior no depende sólo de la cantidad de egresados, sino que también de su calidad, en el sentido que cuenten con las competencias 
GRÁFICO N ${ }^{\circ}$ 13: ESTUDIANTES QUE TERMINARON IV MEDIO EL AÑO ANTERIOR (Miles de estudiantes)

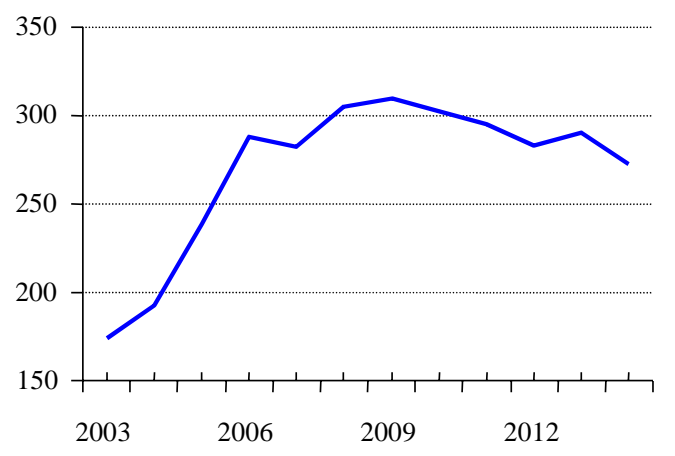

Fuente: Elaborado por los autores sobre la base de matrículas de enseñanza media y básica 2002.

requeridas por el sistema productivo. Desde esta perspectiva, el desafío para las políticas públicas consiste en asegurar conocimientos y competencias similares para los egresados de una misma carrera, de manera de reducir las asimetrías de información que enfrentan tanto los postulantes al elegir carreras y centros de estudios, como los empleadores al contratar trabajadores titulados. Para estos fines resulta imprescindible la vigencia de un sistema de acreditación para la educación superior, un sistema nacional de certificación de competencias laborales, y mayores exigencias para los organismos que proveen educación para el trabajo.

Con todo, la principal fuente de preocupación respecto a la educación superior es la existencia de diferenciales de rentabilidad excesivamente altos. Éstos no sólo ayudan a explicar la desigualdad distributiva, sino que son indicativos de distorsiones que amenazan con prolongar dicha desigualdad en el tiempo, perjudicando también las posibilidades de crecimiento futuro del país. Lo anterior tiene que ver con la falta de equidad en el acceso a la educación superior. Aunque desde 1990 la proporción de jóvenes del $40 \%$ más pobre de la población que accede a la educación superior prácticamente se triplicó — pasó de 4,4\% a $14,5 \%$ en el primer quintil de ingresos y de $7,8 \%$ a $21,2 \%$ en el segundo-, la brecha de acceso entre este grupo y el $20 \%$ más rico no se ha reducido. A la luz de la alta rentabilidad privada de la educación, esto significa que el desarrollo del sistema de educación superior no está ayudando a generar mayor equidad para el futuro.

La persistencia de amplias brechas sociales en el acceso a la educación superior puede ser en parte reflejo de diferenciales en la calidad de la 
educación recibida por los jóvenes en su paso por el sistema escolar ${ }^{59}$ y de presiones para que éstos ingresen directamente al mercado del trabajo una vez egresados de la educación secundaria. Sin embargo, también parece tener incidencia la forma en que se distribuyen los apoyos que entrega el sistema a sus estudiantes. En efecto, los estudiantes universitarios provenientes del $40 \%$ más pobre de los hogares captan en la actualidad sólo un $30 \%$ de los recursos disponibles de apoyo en la forma de becas y créditos.

\section{Lineamientos de política}

Chile comenzó a experimentar un crecimiento alto y sostenido desde que sentó las bases de una estrategia de desarrollo compatible con sus ventajas comparativas y ordenó sus políticas macroeconómicas. Cuando lo anterior se complementó con un Estado no prescindente, corrector de fallas de mercado, proveedor de bienes e infraestructura pública, así como de protección social, también se comenzaron a evidenciar avances en términos de equidad, principalmente en lo referido a reducción de la pobreza. Sin embargo, a pesar de los éxitos de los últimos veinte años, existen limitantes e imperfecciones en el modelo de desarrollo que deben ser enfrentadas de manera proactiva.

Siguiendo la experiencia de los países desarrollados que surgieron desde una posición relativamente similar a la chilena — como por ejemplo los escandinavos-, se infiere que el camino a seguir debe ser la economía del conocimiento en torno a los recursos naturales. En este sentido, parece ser ahora el momento correcto para avanzar en esta senda, por cuanto hay precondiciones que Chile ha ido cumpliendo. Primero, se cuenta con una estabilidad macroeconómica e institucional que sustenta un bajo nivel de riesgo país y una baja volatilidad, lo que sumado al imperio de la ley y al respeto a los derechos de propiedad, sirve de marco base para incentivar las inversiones. Segundo, cuenta con un sistema de precios no distorsionado que minimiza las pérdidas de eficiencia. Tercero, ha desarrollado su infraestructura pública de manera de facilitar las labores productivas. Cuarto, cuenta con un SNI, que aunque inmaduro, contiene un grupo de programas y fondos eficientes que sirve de base para mejorar su desempeño como sistema. Quinto, cuenta con un mercado de capitales debidamente regulado

59 Esto explica en parte las dramáticas diferencias observadas en las pruebas de acceso a la educación superior. Por ejemplo, en el año 2000 el 57,6\% de los estudiantes del primer quintil que rindió la PAA obtuvo un puntaje menor a 457,5; mientras que en el quinto quintil este porcentaje fue de sólo $16,3 \%$. 
y con un desarrollo creciente, que sirve como base para avanzar en el financiamiento del emprendimiento innovador. $\mathrm{Y}$ sexto, ha evidenciado mejoras notables en la cobertura educacional, debiendo abocarse ahora a mejorar la calidad del sistema y a distribuir más equitativamente las habilidades que surgen de la educación terciaria.

Por lo tanto, Chile se encuentra en una posición expectante, a partir de la cual es menester innovar para crecer y, a la vez, invertir en capital humano para innovar. No obstante, la educación es sólo condición necesaria, porque educar sin innovar no genera crecimiento. Si logramos avanzar simultáneamente en educación e innovación, el crecimiento tendrá un nuevo engranaje con la equidad, pues no sólo proveerá los recursos necesarios para financiar las políticas asistenciales, sino que además conseguirá disminuir las inequidades de capital humano, fuente principal del diferencial de renta en Chile.

Desde esta posición surgen tres lineamientos generales de política:

\section{A. Construir la economía del conocimiento es una tarea público-privada que debe basarse en un enfoque sistémico.}

La economía del conocimiento debe sustentarse en tres pilares: (i) un régimen institucional y de incentivos económicos claro, coherente y estable; (ii) una fuerte capacidad de innovación, orientada a desarrollar encadenamientos productivos en torno a ventajas comparativas; y (iii) un capital humano de calidad.

Estos tres pilares están fuertemente interrelacionados entre sí, representando el primero - régimen institucional - el marco para los otros dos — capacidad de innovación y desarrollo del capital humano-, y requiriendo estos últimos de avances en paralelo. Así, sin un régimen institucional claro, coherente y estable, es improbable que existan los incentivos para invertir en el sector productivo, en actividades innovativas, o en capital humano. Por otra parte, sin una demanda por capital humano de mayor calidad por parte del sector productivo, no resulta rentable invertir en educación, o puede ser más rentable ofrecer las habilidades laborales en el exterior. Y viceversa, sin una oferta de capital humano calificado, la capacidad innovativa del sector productivo se ve limitada por su poca adaptabilidad a los cambios y por su deficiente capacidad para usar, adoptar y adaptar las tecnologías externas. Incluso, dada la desigual distribución de capital humano existente en el país, un avance sólo en progreso tecnológico implica el riesgo de exacerbar las desigualdades de ingreso. Esta estrategia de desarrollo basada en estos tres pilares es el polo opuesto de la que el 
país siguiera entre los años 30 y los 70 —esto es, una industrialización forzada inconsistente con sus ventajas comparativas-, pero representa y requiere un salto cualitativo respecto de la situación actual en capacidad de innovación y formación de capital humano.

La institucionalidad es relevante para abordar eficientemente este salto, así como para sumar los esfuerzos públicos y privados. Es necesaria una institucionalidad que dé directrices consistentes y coordine las políticas públicas pro innovación y aquellas destinadas al desarrollo de capital humano, orientando los esfuerzos hacia objetivos estratégicos. Esta institucionalidad debe también crear los incentivos adecuados para movilizar a los distintos actores relevantes - gobierno, empresas, trabajadores, científicos, educadores, instituciones financieras, entre otros-, y desarrollar el capital social y la confianza que permita la colaboración público-privada y entre privados. En definitiva, debe ayudar a alcanzar un acuerdo social amplio en torno a la estrategia de desarrollo.

Para estos propósitos, una solución institucional eficiente pasa necesariamente por asignar claramente la responsabilidad del diseño y la coordinación de las políticas pro economía del conocimiento — responsabilidad diferente a la ejecución de programas específicos, que puede corresponder a organismos diferentes. Complementariamente, quien sea determinado como responsable debe contar también con herramientas suficientes para hacer cumplir sus directrices. En este sentido, un modelo a considerar y adaptar puede ser el seguido por Finlandia — país líder en la economía del conocimiento-, el que cuenta con un consejo ("The Science and Technology Policy Council of Finland") ${ }^{60}$ que asesora a los distintos organismos ejecutores de programas en materias de ciencia y tecnología. Este consejo es responsable del desarrollo estratégico y la coordinación de la política nacional de ciencia y tecnología, así como del SNI como un todo. En Chile, una institucionalidad como la descrita debiese reorganizar el SNI, corrigiendo sus actuales problemas, a saber, falta de directrices, descoordinación, duplicidad de funciones, bajo esfuerzo total, dispersión de programas que no alcanzan a crear masa crítica, baja participación del sector privado, sesgo hacia la investigación básica, falta de financiamiento, "cuellos de botella” en materia de capital humano, y desconexión entre el ámbito empresarial y el ámbito investigador-académico.

${ }^{60}$ El consejo es presidido por el Primer Ministro y está compuesto además por siete ministros y diez personalidades destacadas en el ámbito de la ciencia y la tecnología. Para mayores detalles, véase www.minedu.fi/minedu/research/organisation/sci_tech_council/ sci_tech_council.html 


\section{B. Las políticas de fomento a la innovación deben tener justificación económica y orientarse a la competitividad.}

Las políticas pro innovación presentan una base conceptual y empírica que justifica que éstas sean un ámbito de políticas públicas. Así, éstas deben abocarse a la corrección de las fallas de mercado y las fallas sistémicas que hacen que se innove menos que lo socialmente óptimo. Entre estas fallas cabe destacar la insuficiente apropiabilidad de los beneficios de las innovaciones; las asimetrías de información, altos costos de transacción y de coordinación que limitan la cooperación; las externalidades de red que impiden alcanzar masas críticas; y la alta incertidumbre no cuantificable, la intangibilidad de los activos y los mercados financieros incompletos, que limitan el financiamiento del emprendimiento innovador. Consistentemente, se debe ser estricto en evitar que las políticas pro innovación encubran intervenciones gubernamentales sin una clara justificación económica. Una aplicación concreta de este principio debe darse en el caso de las políticas de apoyo a las PYME.

En esta misma línea, las políticas pro innovación deben vincularse con ventajas comparativas reales reveladas por el propio mercado, y no pretender forzar al país a competir en sectores con improbables alternativas de éxito. Así, trabajar en torno a clusters dinámicos e innovadores construidos alrededor de recursos naturales abundantes resulta consistente con nuestras ventajas comparativas, en contraste con hacerlo en manufacturas intensivas en mano de obra semi-calificada, donde países como China e India tienen una ventaja evidente. Más aún, en vez de los encadenamientos hacia adelante, parecen más en línea con nuestras ventajas comparativas los encadenamientos hacia atrás y los costados de los sectores exportadores en que Chile ya es líder -como ha ocurrido en el caso de la salmonicultura, donde la industria de alimento de peces ya es también exportadora. Ello, por cuanto los encadenamientos hacia atrás y los costados tienen ventajas de escala y de cercanía geográfica a la demanda que los encadenamientos hacia adelante no tienen. Un claro ejemplo es la demanda por insumos y servicios para la minería del cobre, donde Chile posee más del $35 \%$ de las reservas mundiales. Un efecto adicional de esta focalización en clusters construidos en torno a recursos naturales es el desarrollo regional que conlleva, por la misma localización de estos recursos.

El enfoque de la innovación orientada a la competitividad implica también evitar asociar innovación sólo con la generación o creación de nuevas tecnologías. Si bien en los sectores en que Chile es líder puede ser necesario estar en la frontera del conocimiento, debe tenerse presente que la innovación implica principalmente adoptar y adaptar tecnologías exter- 
nas, lo que es relevante por tener un costo significativamente menor. Esto es cierto incluso para los países desarrollados — por ejemplo, en EE.UU. los recursos destinados a adoptar tecnologías externas son 30 veces los dedicados a innovar en la frontera. Esta consideración implica que el esfuerzo innovador del país debe cambiar su foco desde la investigación básica hacia la investigación aplicada en sintonía con las necesidades empresariales. Y las políticas públicas deben ser capaces de generar los incentivos correctos para que ello ocurra.

La orientación de las políticas pro innovación a la competitividad puede requerir también un enfoque pragmático ${ }^{61}$ y ad hoc ${ }^{62}$ para resolver algunas fallas sistémicas y de mercado específicas. Este enfoque pragmático requiere de un Estado confiable, transparente y riguroso en evaluar sus intervenciones, debiendo terminarlas o reformularlas, tanto porque prueben ser ineficientes, como porque queden superadas por el desarrollo del propio mercado. En definitiva, el Estado debe ser capaz de aprender de sus errores, y evitar las "fallas de gobierno", tales como su captura por parte de grupos de interés, o el intervencionismo inconsistente con el mercado, como "la elección de sectores ganadores".

Finalmente, se recalca que el país debe materializar un mayor esfuerzo de movilización de recursos para fomentar la innovación, más allá de las ganancias de eficiencia que puedan lograrse por la racionalización del SNI. En efecto, en el ámbito de la investigación y desarrollo el país presenta un rezago significativo respecto a lo esperado para su nivel de ingreso, siendo éste mucho más dramático que lo observado en ámbitos como el gasto público en educación. En este sentido, se estima que Chile debe cerrar una brecha de al menos 2,4 puntos porcentuales del PIB para alinearse con los países líderes en innovación. En particular, el sector público debiese duplicar su gasto en investigación y desarrollo, pasando de $0,4 \%$ del PIB a $0,8 \%$, debiendo el sector privado hacerse cargo del resto de la brecha. Esto implica que el sector público debe aumentar su esfuerzo innovador en una cifra entre US\$300 millones y US\$400 millones al año.

${ }^{61} \mathrm{El}$ enfoque pragmático puede requerirse, por ejemplo, para solucionar las fallas que limitan el financiamiento del emprendimiento innovador. En este mercado se ha avanzado por una parte en proveer fondos públicos para apoyar la generación de ideas y, por otra, en desarrollar el mercado de capital de riesgo para que inversionistas privados puedan transformar estas ideas en negocios. Sin embargo, persiste un rezago en el desarrollo del capital semilla para el financiamiento de los primeros escalamientos de los proyectos innovadores, el que en países como Suecia e Israel —líderes en innovación - se materializa a través de la adquisición de una participación en su propiedad por parte del Estado, pero con un rol debidamente acotado por evaluaciones sistemáticas y condiciones "de salida" objetivas previamente definidas.

${ }^{62} \mathrm{El}$ enfoque ad hoc puede requerirse, por ejemplo, para apoyar el desarrollo de clusters que enfrentan distintos "cuellos de botella" específicos a su sector. 


\section{El sistema educacional debe mejorar su calidad y equidad de acceso, con énfasis en la efectividad y focalización de los apoyos públicos.}

El momento para concentrar esfuerzos en el mejoramiento de la calidad y equidad de la educación es precisamente ahora, cuando los problemas de acceso a la escuela están en buena medida resueltos. Además, hoy existe una ventana de oportunidad que abre la demografía. En efecto, el largo ciclo de expansión de la población en edad escolar se encuentra próximo a terminar, disminuyendo la presión cuantitativa sobre el sistema educacional y sobre los gastos de funcionamiento del mismo. Proyecciones para el período 2005-2020 indican que si el gasto en educación continuase creciendo al ritmo de los últimos 10 años -6,1\% promedio anual-, podrían alcanzarse, simultáneamente, niveles de cobertura de educación prebásica y superior equivalentes a los de países avanzados y un gasto por estudiante igual a 2,6 veces el actual.

Lo anterior, sin embargo, no asegura un avance en la calidad y equidad de la educación. Para ello son necesarias dos condiciones adicionales: primero, que los recursos incrementales no sean absorbidos por escalamientos de costos que sólo beneficien a los proveedores del sistema y, segundo, que dichos recursos sean invertidos de manera efectiva y focalizada. Esto hace necesaria una síntesis positiva de las reformas financiera y pedagógica de los últimos 25 años, lo que a su vez requiere que se dejen de lado los prejuicios ideológicos que han marcado la discusión durante muchos años y se realicen intervenciones de naturaleza distinta a las efectuadas hasta ahora.

En primer lugar, es necesario elevar las exigencias para acceder a la subvención estatal. Del mismo modo, un sistema educacional tan descentralizado como el chileno, donde la libertad que una familia tiene para elegir la escuela de sus hijos depende de la disponibilidad real de alternativas y medios para acceder a ellas, requiere de un reforzamiento de los estándares de logros de aprendizaje —entendidos como mínimos absolutos que sean a la vez una exigencia para las escuelas y una garantía para los niños que asisten a ellas. Igualmente válido en este sentido es la aplicación de estándares mínimos sobre las competencias de los docentes, lo que requiere medios de verificación o acreditación independientes y de amplias oportunidades de perfeccionamiento concentradas en la actualización de conocimientos en disciplinas sustantivas. Un sistema de estándares mínimos de logro educativo y de formación y desempeño docente requiere, además, de estímulos y sanciones para ser realmente efectivo. 
Por otra parte, es necesario que el Estado asuma entre sus funciones la de proveer información sustantiva que apoye las decisiones de las familias. Para ello se requiere desarrollar una verdadera ficha escolar que refleje las distintas dimensiones del desempeño de la escuela y el valor que ésta agrega en los procesos de aprendizaje de sus alumnos. Además, se requiere de un sistema de supervisión eficaz de las escuelas descentralizadas, rediseñando profundamente el sistema vigente.

Finalmente, si el sistema educacional va a ayudar a reducir las inequidades de origen que condicionan las capacidades de los niños para aprender, no es suficiente que se financie con una subvención uniforme. Compensar las desventajas de origen requiere de una atención más personalizada en la escuela y profesores más efectivos, apoyados por profesionales de otras áreas. Para cubrir el mayor costo que esto involucra es necesario que exista una subvención diferenciada para los niños de menores recursos.

Para responder a las demandas de la economía del conocimiento se requieren también mejoras de calidad y equidad de acceso en la educación superior. Para avanzar en esta dirección se requieren dos condiciones: primero, que los recursos liberados por el estancamiento de la población escolar no sean absorbidos por escalamientos de costos de los prestadores $\mathrm{y}$, segundo, que se produzca una adecuada complementación de recursos públicos y privados en el financiamiento de la educación superior. La complementación del esfuerzo estatal con recursos privados tiene directa relación con la constatación de altas tasas de retorno privado para la inversión en educación superior, las que además se materializan en períodos más breves que para los niveles primario y secundario. Esto indica que endeudarse para financiar sus estudios superiores es una decisión altamente rentable para un individuo. Para que ello sea factible, sin embargo, es necesario resolver las fallas de mercado asociadas a la inversión en capital humano. Un efecto secundario de la viabilización de sistemas sostenibles de crédito universitario sería generar el espacio fiscal necesario para concentrar los aportes directos del estado en la aplicación de estímulos para que jóvenes de menores recursos ingresen efectivamente a la educación superior. Con todo, para ello se requiere mejorar significativamente la capacidad de focalización de estos apoyos respecto de lo que se aprecia en la actualidad. 


\section{BIBLIOGRAFÍA}

Acemoglu, D.: "Why do New Technologies Complement Skills? Directed Technical Change and Wage Inequality". The Quarterly Journal of Economics. Vol. 113, pp. 10551089, nov. 1998.

Alfaro, L. y Rodríguez-Clare, A.: "Multinationals and Linkages: An Empirical Investigation". Research Department, Inter-American Development Bank, 2003.

Alternburg, T. y Meyer-Stamer, J.: "How to Promote Clusters: Policy Experiences from Latin America”, World Development, Vol. 27 № 9 (1999), pp. 1693-1713.

Alvarez, R.: "Explaining Export Success: Firm Characteristics and Spillover Effects". Mimeo, 2004.

Barro, R.: "Determinants of Economic Growth: Implications of the Global Evidence for Chile", Cuadernos de Economía, 36 (107), 1999.

Benavente, J. M.: “Antecedentes para el Diseño de una Política Tecnológica Nacional”, Mimeo, 2004a.

Benavente, J. M.: "Innovación Tecnológica en Chile: Dónde Estamos y Qué se Puede Hacer". Documento de Trabajo 295. Banco Central de Chile, 2004b.

Benavente, J. M. y G. Crespi: "The Impact of an Associative Strategy on Small and Medium Enterprises in Chile". Trabajo presentado en 56th European Meeting of the Econometric Society, Lausanne, 2002.

Beyer, H. y Vergara, R.: "Productivity and Economic Growth: the Case of Chile". En N. Loayza y R. Soto (editores), Economic Growth. Sources, Trends and Cycles. Series on Central Banking, Analysis and Economic Policies, Banco Central de Chile, 2002.

Blomstrom, M. y Meller, P. (editores): Diverging Paths: Comparing a Century of Scandinavian and Latin American Economic Development. Inter-American Development Bank y Johns Hopkins University Press, 1991.

Bloom, D., Canning, D. y Sevilla, J.: “Technological Diffusion, Conditional Convergence, and Economic Growth”. NBER Working Paper N 8713, 2002.

Bosch, M., Lederman, D. y Maloney, W.: "Patenting and Efficiency: A Global View". World Bank Working Paper No 3024, 2004.

Braun, J., Braun, M., Briones, I. y Díaz, J.: "Economía Chilena 1810-1995: Estadísticas Históricas". Documento de Trabajo N 187, Instituto de Economía PUC, 2000.

Bravo-Ortega, C. y De Gregorio, J.: "The Relative Richness of the Poor? Natural Resources, Human Capital and Economic Growth". Banco Central de Chile, Working Paper $\mathrm{N}^{\circ} 139,2004$.

Brunner, J. J. y Elacqua, G.: Informe Capital Humano en Chile. Universidad Adolfo Ibáñez, Escuela de Gobierno, 2003.

Bruton, H.: "A Reconsideration of Import Substitution". Journal of Economic Literature, Vol. XXXVI (1998), pp. 903-936.

Crespi, G y Muñoz, G.: "La Contribución del Fondo de Desarrollo e Innovación al Crecimiento Económico", CORFO, 1998.

De Ferranti, D., Perry, G., Gill, I., Guash, J. L., Maloney, W., Sánchez-Páramo, C. y Schady, N.: Closing the Gap in Education and Technology. World Bank, 2003.

De Ferranti, D., Perry, G., Lederman, D. y Maloney, W.: De los Recursos Naturales a la Economía del Conocimiento: Comercio y Calidad del Empleo. Banco Mundial, 2002.

Di Tommaso, M. y Dubbini, S.: "Towards a Theory of the Small Firm: Theoretical Aspects and some Policy Implications". Serie Desarrollo Productivo No 87, CEPAL, 2000. 
Fajnzylber, F.: "Industrialización en América Latina: de la Caja Negra al Casillero Vacío". Cuadernos CEPAL Nº 60 (1990).

Ffrench Davis, R.: Entre el Neo-liberalismo y el Crecimiento con Equidad: Tres Décadas de Política Económica en Chile. Santiago: Ediciones Dolmen, 2003.

Gallego, F. y Loayza, N.: "La Época Dorada del Crecimiento en Chile: Explicaciones y Proyecciones". Revista Economía Chilena, Vol. 5 № 1 (2002), Banco Central de Chile.

Georghiou, L., Smith, K., Toivanen, O. y Yla-Anttila, P.: Evaluation of the Finish Innovation Support System. Ministry of Trade and Industry of Finland, 2003.

Gerens: "FONTEC-Innovación Tecnológica: Una Evaluación de sus Beneficios Sociales". Mimeo, 1996a.

Gerens: "FONDEF-Innovación Pre-competitiva: Una Estimación de sus Beneficios Sociales". Mimeo, 1996b.

Gill, I.: "An Economic Approach to the Knowledge Economy: Technology-Skill Complementarities and their Implications for Productivity and Policy". Background paper para De Ferranti et al. (2003).

Hall, B.: "Investment and Research and Development: Does the Source of Financing Matter?". Working Paper $N^{\circ}$ 92-194, Department of Economics, University of California at Berkeley, 1992.

Hallberg, K.: "A Market-Oriented Strategy for Small and Médium-Scale Enterprises". IFC Discussion Paper $\mathrm{N}^{\circ}$ 40, World Bank, 2000.

Hao, K. y Jaffe, A.: “Effect of Liquidity on Firms' R\&D Spending”. Economics of Innovation and New Technology, 2 (1993), pp. 275-282.

Hirschman, A.: The Strategy of Economic Development. Yale University Press, 1958.

Krugman, P.: Geography and Trade. MIT Press, 1991.

Lederman, D. y Maloney, W.: “Innovación en Chile: ¿Dónde Estamos?”. Serie En Foco No 18, Corporación Expansiva, 2004.

Lederman, D. y Maloney, W.: "R \& D and Development". Mimeo, 2003.

Lockheed, M. E. y Verspoor, A. M.: Improving Primary Education in Developing Countries. World Bank, 1991.

Lora, E. y Panizza, U.: "Structural Reforms in Latin America under Scrutiny". BID Working Paper $\mathrm{N}^{\circ}$ 470, 2002.

Martin, W. y Mitra, D.: "Productivity Growth and Convergence in Agriculture and Manufacturing”. En Economic Development and Cultural Change, 49 (2), 2001.

Matsuyama, K.: "Agricultural Productivity, Comparative Advantage, and Economic Growth". En Journal of Economic Theory, $\mathrm{N}^{\circ} 58$ (1992).

Meller, P.: Un Siglo de Economía Política Chilena (1890-1990). Editorial Andrés Bello, 1998.

Mineduc: "Competencias para la Vida: Resultados de los Estudiantes Chilenos en el Estudio PISA 2000". Unidad de Currículum y Evaluación, 2004.

Mizala, A., y Romaguera, P.: "Remuneraciones al Pizarrón". En Revista Perspectivas en Política, Economía y Gestión, Vol. 4, № 1 (2000).

Mizala, A., Romaguera, P. y Farren, D.: "Eficiencia Técnica de los Establecimientos Educacionales en Chile". Documentos de Trabajo, Serie Economía Nº 38, Universidad de Chile, Departamento de Ingeniería Industrial, 1998.

Montero, C.: "Formación y Desarrollo de un Cluster Globalizado: El Caso de la Industria del Salmón en Chile". Serie de Desarrollo Productivo N 145, CEPAL, 2004.

OCDE: "Estudios Económicos OCDE: Chile". Noviembre 2003. 
Palmberg, C.: "The Transformation of the Forestry-related Industries: A Knowledge Economy Viewpoint". Mimeo, 2004.

Psacharopoulos, G. y Patrinos, H. A.: "Returns to Investment in Education: a Further Update", World Bank Policy Research Working Paper N²881, 2002.

Ramos, J.: "Una Estrategia de Desarrollo a Partir de los Complejos Productivos (Clusters) en torno a los Recursos Naturales, ¿Una Estrategia Prometedora?”. CEPAL, División de Desarrollo Productivo y Empresarial, 1999.

Rodríguez-Clare, A.: "Microeconomic Interventions after the Washington Consensus". Research Department, Inter-American Development Bank, 2004.

Rodrik, D.: "Trade and Industrial Policy Reform". En Handbook of Development Economics, Vol. III, B, North-Holland, 1995.

Romer, P.: "Endogenous Technological Change". En Journal of Political Economy $\mathrm{N}^{\circ} 98$ (1990).

Rouvien, P.: "R\&D-Productivity Dynamics: Causality, Lags, and Dry Holes". Journal of Applied Economics, Vol. V, No 1, pp. 123-156, May 2002.

Sachs, J. y Warner, A.: "Natural Resource Abundance and Economic Growth". NBER Working Paper $\mathrm{N}^{\circ}$ 5398, 1995.

Schieffelbein, E., Wolff, L. y Schieffelbein, P.: "Cost-Effectiveness of Education Policies in Latin America: A Survey of Expert Opinion”. N-EDUC 109, BID, 1998.

Schmitz, H.: "Collective Efficiency: Growth Path for Small-Scale Industry". En Journal of Development Studies, 31 (4), 1995, pp. 529-566.

Stiglitz, J. E.: "The Role of the State in Financial Markets". World Bank Annual Conference on Development Economics, 1993.

Sunkel, O. (compilador): El Desarrollo desde Dentro: Un Enfoque Neo-estructuralista para América Latina. Fondo de Cultura Económica, 1991.

Tokman, A.: "Is Private Education Really Better? Evidence from Chile". Working Paper $\mathrm{N}^{\circ}$ 142. Banco Central de Chile, 2002.

Tokman, M. y Zahler, A.: "Innovación para un Crecimiento Sostenido: Siete Lecciones para Chile". Serie En Foco No 20, Corporación Expansiva, 2004.

Ulloa, A.: "Clusters de Recursos Naturales en Chile: Una Opción para la Segunda Fase Exportadora". Mimeo, 2004.

Universidad de Chile: "Evaluación de Impacto Fondo de Desarrollo e Innovación". Dirección de Presupuestos, Ministerio de Hacienda, 2004.

Universidad de Chile: "Evaluación de los Resultados Económicos de los Proyectos de Innovación Tecnológica Financiados por el FONTEC". CORFO, 2004b.

World Bank: "Chile, New Economy Study". Report No 25666-CL, 2004.

World Bank: Priorities and Strategies for Education. World Bank Review, 1995. 